\title{
A Structural Study of Epoxidized Natural Rubber (ENR-50) and Its Cyclic Dithiocarbonate Derivative Using NMR Spectroscopy Techniques
}

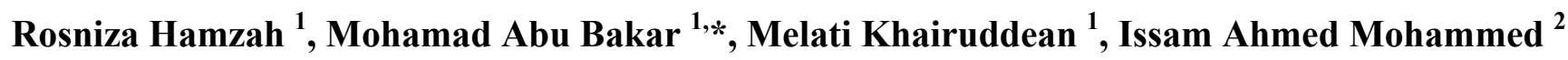 \\ and Rohana Adnan ${ }^{1}$ \\ 1 Nanoscience Research Laboratory, School of Chemical Sciences, Universiti Sains Malaysia, \\ Penang 11800, Malaysia \\ 2 School of Industrial Technology, Universiti Sains Malaysia, Penang 11800, Malaysia \\ * Author to whom correspondence should be addressed; E-Mail: bmohamad@usm.my; \\ Fax: +604-657-4854.
}

Received: 17 August 2012; in revised form: 3 September 2012 / Accepted: 3 September 2012 / Published: 12 September 2012

\begin{abstract}
A structural study of epoxidized natural rubber (ENR-50) and its cyclic dithiocarbonate derivative was carried out using NMR spectroscopy techniques. The overlapping ${ }^{1} \mathrm{H}-\mathrm{NMR}$ signals of ENR-50 at $\delta 1.56,1.68-1.70,2.06,2.15-2.17 \mathrm{ppm}$ were successfully assigned. In this work, the ${ }^{13} \mathrm{C}-\mathrm{NMR}$ chemical shift assignments of ENR-50 were consistent to the previously reported work. A cyclic dithiocarbonate derivative of ENR-50 was synthesized from the reaction of purified ENR-50 with carbon disulfide $\left(\mathrm{CS}_{2}\right)$, in the presence of 4-dimethylaminopyridine (DMAP) as catalyst at reflux temperature. The cyclic dithiocarbonate formation involved the epoxide ring opening of the ENR-50. This was followed by insertion of the $\mathrm{C}-\mathrm{S}$ moiety of $\mathrm{CS}_{2}$ at the oxygen attached to the quaternary carbon and methine carbon of epoxidized isoprene unit, respectively. The bands due to the $\mathrm{C}=\mathrm{S}$ and $\mathrm{C}-\mathrm{O}$ were clearly observed in the FTIR spectrum while the ${ }^{1} \mathrm{H}-\mathrm{NMR}$ spectrum of the derivative revealed the peak attributed to the methylene protons had split. The ${ }^{13} \mathrm{C}$-NMR spectrum of the derivative further indicates two new carbon peaks arising from the $>\mathrm{C}=\mathrm{S}$ and quaternary carbon of cyclic dithiocarbonate. All other ${ }^{1} \mathrm{H}$ - and ${ }^{13} \mathrm{C}-\mathrm{NMR}$ chemical shifts of the derivative remain unchanged with respect to the ENR-50.
\end{abstract}

Keywords: ENR-50; 2D NMR; triad sequence; cyclic dithiocarbonate 


\section{Introduction}

Epoxidized natural rubber (ENR) is a modified natural rubber (NR) [1]. A typical formation of ENR from NR, cis-1,4-isoprene, employing peracetic acid is shown in Scheme 1a [2]. The isoprene (C) and epoxidized isoprene (E) act as monomer units that are randomly distributed along the polymer chain [1]. Various degree of epoxidation of NR is commercially available. For examples, the isoprene units in the polymer chain are $25 \%, 50 \%$ and $75 \%$ epoxidized in ENR-25, ENR-50 and ENR-75, respectively. For the purpose of nomenclature, the general structure and the numbering of carbon atoms in ENR-50 is shown in Scheme 1b.

Scheme 1. (a) Modification of NR to ENR [2] and (b) the general structure and the numbering of carbon atom in ENR-50 employed in this work.

(a)

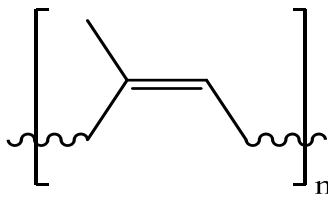

isoprene

$\mathrm{C}$

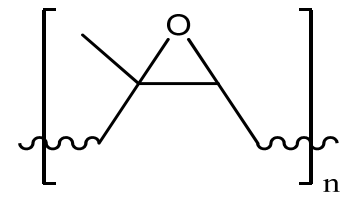

epoxidized isoprene

$\mathrm{E}$

(b)

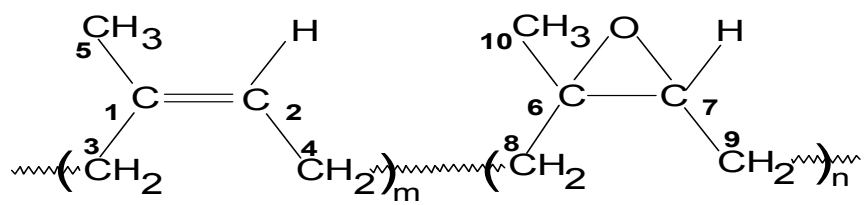

NMR spectroscopy techniques are widely used to characterize various polymers either in liquid or solid state. Characterization using 1D NMR gives structural elucidation on reactive groups and monomer units in the polymer chain. However, the 2D NMR extents detail structural arrangements of the monomer units within the polymer chain. Either or both of these techniques have been applied to ENR-25 [3], ENR-50 [4-9], and ENR-75 [6], and other ENR-related compounds [10]. However, most of these works fall short of full structural assignments due to the overlapping of signals arising from the randomly distributed $\mathrm{C}$ and $\mathrm{E}$ monomer units [11,12].

The random arrangement of $\mathrm{C}$ and $\mathrm{E}$ units within the ENR chains give rise to several probable sequences. This inevitably makes the structural interpretation via the NMR techniques difficult. To overcome this, Bradbury and Perera [12] have established a procedure of grouping the randomly located monomer units into triad sequence. A triad is made up of three possible monomer units. All possible triad sequences of ENR-50 are shown in Figure 1.

In a triad, the neighboring units may dictate the ${ }^{1} \mathrm{H}$ and ${ }^{13} \mathrm{C}$ environments of the middle unit. It is the middle unit that will reveal the triad structure. For example, an ENR chain fragment may comprise of $\mathrm{C}$ unit attached to an $\mathrm{E}$ unit which in turn is attached to another $\mathrm{E}$ unit. Thus, this triad sequence is denoted as CEE. Triad comprising of similar unit is only denoted by a single unit. Triad CCC is denoted as $\mathrm{C}$ and triad EEE is denoted as $\mathrm{E}$. The methyl of the middle unit in the CEE and CCC triads are referred to as $\mathrm{CE}^{10} \mathrm{E}$ and $\mathrm{C}^{5}$, respectively, and the methylene carbon of $\mathrm{C}^{3}$ refers to the third carbon in the ENR-50 structure as shown in Scheme 1b. This also applies to the proton in the ENR-50 structure. 
Figure 1. The possible triad sequence of ENR-50.
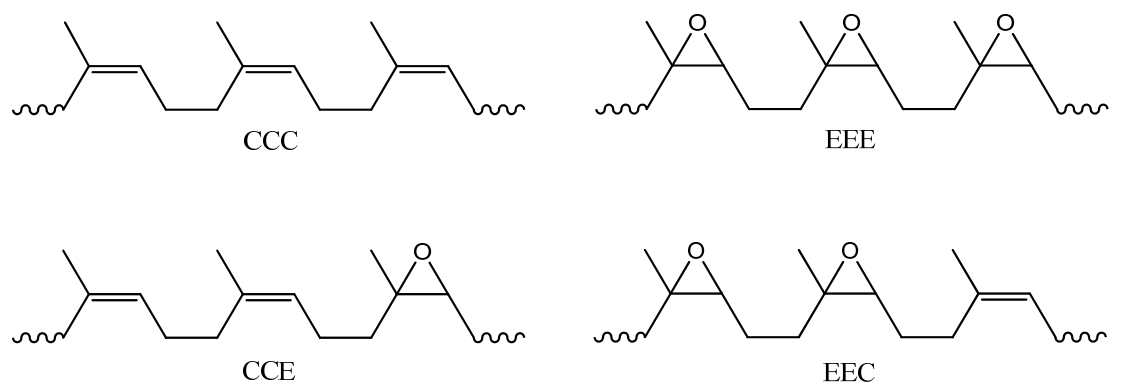

EEC
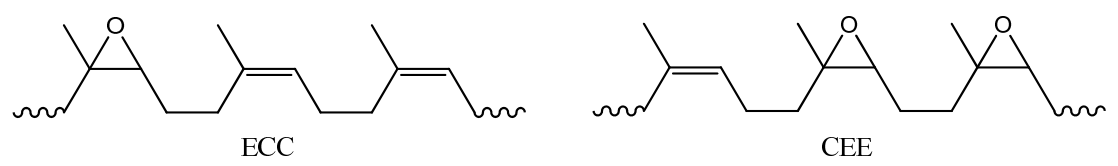

CEE

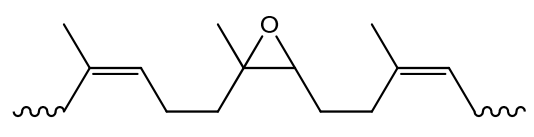

CEC

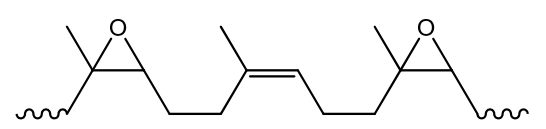

ECE

Thus prior to the advent of the triad sequence, previous workers [6-9,12,13] were only able to ascertain the assignments of ${ }^{1} \mathrm{H}-\mathrm{NMR}$ chemical shifts of the methine proton of $\mathrm{C}$ and $\mathrm{E}$ units but sporadically to either the methyl and or methylene protons of $\mathrm{C}$ and $\mathrm{E}$ of the ENR. Saito et al. [11] have reported the use of computer simulation $[14,15]$ to predict chemical shifts of these protons and their triad assignments.

Gelling [2], on the other hand, has assigned the triad sequence based on ${ }^{13} \mathrm{C}-\mathrm{NMR}$ chemical shifts for ENR-20. However, the assignment deals with certain triad sequences such as CEE, CEC, C, EEC, and ECE and the position of carbon represented by the triad sequences was found to be inconsistent. Consequently, Saito et al. [11] have successfully interpreted the ${ }^{13} \mathrm{C}$-NMR spectra for the ENR related compounds and assigned their triad sequence as shown in Table 1, columns 2 and 4.

The increasing interests in the science and technology of ENR in various fields such as polymer blends [16], polymer modifications [17], polymer composites [18] and advanced green materials [19-21] makes it inevitable to understand the detail structure of ENR. This fundamental study is important to enable comprehensive structural characterization of the desired materials. Here we attempted a complete assignment of the commercial ENR-50 using the 1D and 2D NMR spectroscopy techniques. Our work differs from other reported works [11,22,23] in term of the degree of epoxidation and physical form of rubber. The ENR used is a low molecular weight fraction of ENR-50 obtained by solvent separation [19]. In this work, the results reported by Saito et al. [11] were used for comparison purposes. Apart from the above, this work also reported the structural elucidation of cyclic dithiocarbonate derivative of ENR-50 obtained from the reaction between purified ENR-50 with neat carbon disulfide, $\mathrm{CS}_{2}$ [24]. The reaction is shown in Scheme 2. A complete ${ }^{1} \mathrm{H}-$ and ${ }^{13} \mathrm{C}-\mathrm{NMR}$ chemical shifts assignments of the cyclic dithiocarbonate derivative of ENR-50 is given and the probable mechanism of formation was discussed. 
Table 1. ${ }^{1} \mathrm{H},{ }^{13} \mathrm{C}-\mathrm{NMR}$ chemical shifts and HMQC, HMBC and COSY spin coupling correlations of purified ENR-50.

\begin{tabular}{|c|c|c|c|c|c|c|c|c|c|}
\hline \multicolumn{3}{|c|}{${ }^{1} \mathbf{H}$ chemical shift $\delta(p p m)$} & \multicolumn{2}{|c|}{$\begin{array}{c}{ }^{13} \mathrm{C} \text { chemical shift } \\
\delta(\mathrm{ppm}) \\
\end{array}$} & \multirow{2}{*}{$\begin{array}{c}\text { HMQC } \\
\text { Triad assignment }\end{array}$} & \multicolumn{2}{|c|}{ HMBC Coupling correlation } & \multicolumn{2}{|c|}{ COSY Coupling correlation } \\
\hline $\begin{array}{l}\text { Ref: } \\
14-15\end{array}$ & $\begin{array}{c}\text { Ref: } \\
11\end{array}$ & This work & $\begin{array}{c}\text { Ref: } \\
11\end{array}$ & This work & & $\begin{array}{c}\text { Middle unit } \\
\delta(\mathrm{ppm})\end{array}$ & $\begin{array}{c}\text { Within same unit } \\
\quad \delta(\mathrm{ppm}) \\
\end{array}$ & $\begin{array}{l}\text { Middle unit } \\
\delta(\mathbf{p p m})\end{array}$ & $\begin{array}{c}\text { Within same unit } \\
\quad \delta(\mathbf{p p m})\end{array}$ \\
\hline 1.31 & 1.29 & 1.30 & 22.1 & 22.3 & $E^{10}$ & $29.7\left(\mathrm{E}^{8}\right), 60.7\left(\mathrm{E}^{6}\right), 64.5\left(\mathrm{E}^{7}\right)$ & None & None & None \\
\hline 1.38 & 1.55 & 1.56 & 29.5 & 29.7 & $\mathrm{EE}^{8} \mathrm{C}, \mathrm{E}^{8}$ & $22.3\left(\mathrm{E}^{10}\right), 60.7\left(\mathrm{E}^{6}\right), 64.5\left(\mathrm{E}^{7}\right)$ & $24.7\left(\mathrm{E}^{9}\right), 64.5\left(\mathrm{E}^{7}\right)$ & None & $1.68-1.70\left(E^{9}\right)$ \\
\hline & & & 33.0 & 33.1 & $\mathrm{CE}^{8} \mathrm{C}, \mathrm{CE}^{8} \mathrm{E}$ & $22.3\left(\mathrm{E}^{10}\right), 60.7\left(\mathrm{E}^{6}\right), 64.5\left(\mathrm{E}^{7}\right)$ & $23.9\left(C^{4}\right), 125.0\left(C^{2}\right)$ & None & $2.15-2.19\left(C^{4}\right)$ \\
\hline & & & 26.9 & 27.0 & $\mathrm{CE}^{9} \mathrm{C}, \mathrm{EE}^{9} \mathrm{C}$ & $60.7\left(E^{6}\right), 64.5\left(E^{7}\right)$ & $28.7\left(C^{3}\right), 134.7\left(C^{1}\right)$ & $2.72\left(E^{7}\right)$ & $2.15-2.19\left(C^{3}\right)$ \\
\hline 1.42 & 1.68 & $1.68-1.70$ & 23.3 & 23.4 & $C^{5}$ & $32.0\left(\mathrm{C}^{3}\right), 125.0\left(\mathrm{C}^{2}\right), 134.7\left(\mathrm{C}^{1}\right)$ & None & None & None \\
\hline 1.38 & & & 24.6 & 24.7 & $\mathrm{CE}^{9} \mathrm{E}, \mathrm{E}^{9}$ & $60.7\left(E^{6}\right), 64.5\left(E^{7}\right)$ & $29.7\left(E^{8}\right), 60.7\left(E^{6}\right)$ & $2.72\left(E^{7}\right)$ & $1.56\left(\mathrm{E}^{8}\right)$ \\
\hline 2.00 & 2.05 & 2.06 & 26.2 & 26.3 & $\mathrm{C}^{4}, \mathrm{EC}^{4} \mathrm{C}$ & $125.0\left(\mathrm{C}^{2}\right), 134.7\left(\mathrm{C}^{1}\right)$ & $32.0\left(C^{3}\right), 134.7\left(C^{1}\right)$ & $5.12-5.17\left(\mathrm{C}^{2}\right)$ & $2.06\left(C^{3}\right)$ \\
\hline & & & 32.0 & 32.0 & $\mathrm{C}^{3}, \mathrm{CC}^{3} \mathrm{E}$ & $23.4\left(C^{5}\right), 125.0\left(C^{2}\right), 134.7\left(C^{1}\right)$ & $26.3\left(C^{4}\right), 125.0\left(C^{2}\right)$ & None & $2.06\left(C^{4}\right)$ \\
\hline 1.96 & 2.15 & $2.15-2.19$ & 23.7 & 23.9 & $\mathrm{CC}^{4} \mathrm{E}, \mathrm{EC}^{4} \mathrm{E}$ & $125.0\left(\mathrm{C}^{2}\right), 134.7\left(\mathrm{C}^{1}\right)$ & $33.1\left(E^{8}\right), 60.7\left(E^{6}\right)$ & $5.12-5.17\left(C^{2}\right)$ & $1.56\left(E^{8}\right)$ \\
\hline & & & 28.5 & 28.7 & $\mathrm{EC}^{3} \mathrm{C}, \mathrm{EC}^{3} \mathrm{E}$ & $23.4\left(C^{5}\right), 125.0\left(C^{2}\right), 134.7\left(C^{1}\right)$ & $27.0\left(\mathrm{E}^{9}\right), 64.5\left(\mathrm{E}^{7}\right)$ & None & $1.56\left(\mathrm{E}^{9}\right)$ \\
\hline- & - & - & 60.3 & 60.7 & $E^{6}$ & - & - & - & - \\
\hline 2.51 & 2.70 & 2.72 & 64.0 & 64.5 & $\mathrm{E}^{7}$ & $\begin{array}{c}22.3\left(\mathrm{E}^{10}\right), 24.7\left(\mathrm{E}^{9}\right), 29.7\left(\mathrm{E}^{8}\right) \\
60.7\left(\mathrm{E}^{6}\right)\end{array}$ & $29.7\left(\mathrm{E}^{8}\right),($ None $)$ & $1.68-1.70\left(\mathrm{E}^{9}\right)$ & None \\
\hline 5.20 & 5.10 & $5.12-5.17$ & 125.0 & 125.0 & $\mathrm{C}^{2}$ & $\begin{array}{l}23.4\left(C^{5}\right), 26.3\left(C^{4}\right), 32.0\left(C^{3}\right) \\
134.7\left(C^{1}\right)(\text { NOT DETECTED) }\end{array}$ & $32.0\left(C^{3}\right)$ & $2.06\left(C^{4}\right)$ & None \\
\hline- & - & - & 135.0 & 134.7 & $\mathrm{C}^{1}$ & - & - & - & - \\
\hline
\end{tabular}


Scheme 2. Reaction of purified ENR-50 with carbon disulfide catalyzed by 4-dimethylaminopyridine (DMAP).

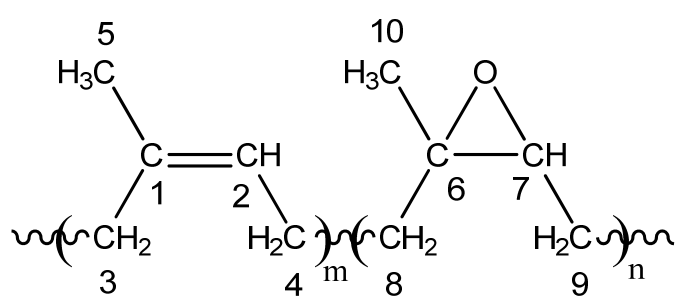

ENR-50

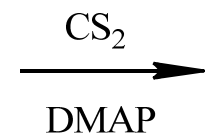

\section{Results and Discussion}

\subsection{Epoxidized Natural Rubber}

\subsection{1. ${ }^{1} \mathrm{H}$ - and ${ }^{13} \mathrm{C}-\mathrm{NMR}$ Spectroscopy}

The ${ }^{1} \mathrm{H}$ - and ${ }^{13} \mathrm{C}-\mathrm{NMR}$ spectra of purified ENR-50 are shown in Figure 2 and the respective chemical shifts are tabulated in Table 1. The respective observed chemical shifts were generally similar to those reported in previous works $[11,14,15]$. From Figure $2 \mathrm{a}$, the ${ }^{1} \mathrm{H}-\mathrm{NMR}$ chemical shift at $\delta 1.30 \mathrm{ppm}$ is assigned to the methyl protons of $\mathrm{E}^{10}$, at $\delta 2.72 \mathrm{ppm}$ to the methine proton of $\mathrm{E}^{7}$ and at $\delta$ 5.12-5.17 ppm to the methine proton of $\mathrm{C}^{2}$. However, the chemical shift at $\delta 1.56 \mathrm{ppm}$ overlapped with those at $\delta 1.68-1.70 \mathrm{ppm}$ while the chemical shift at $\delta 2.15-2.19 \mathrm{ppm}$ overlapped with those at $\delta$ $2.06 \mathrm{ppm}$. These overlapping signals may be due to the methylene protons of the ENR-50 chain. To confirm, a J-resolved spectroscopy (JRES) [25,26] experiment was conducted to specifically investigate the overlapping signals at $\delta 1.68-1.70 \mathrm{ppm}$ region. Figure 3 shows the enlarged JRES spectra of $\delta 1.20-1.80 \mathrm{ppm}$ region. The methyl of $\mathrm{E}^{10}$ is represented as a single contour at $\delta 1.30 \mathrm{ppm}$. The overlapping methylene signal in JRES was represented by a double contour located at $\delta 1.68$ and $1.70 \mathrm{ppm}$, with coupling constant of $11 \mathrm{~Hz}$. The multiple methylene protons signal is due to the different attachment modes of the epoxide to the isoprene which collectively form pairs of the enantiomers, stereoisomers and diastereoisomers that give rise to separate the resonances in the NMR spectrum [12].

The ${ }^{13} \mathrm{C}$-NMR spectrum of purified ENR-50 is shown in Figure 2b. The signals within $\delta 23.9$ to $33.1 \mathrm{ppm}$ represent the doublets of methylene carbons of $\mathrm{C}^{3}, \mathrm{C}^{4}, \mathrm{E}^{8}$ and $\mathrm{E}^{9}$. The methylene carbons of $\mathrm{C}^{4}$ and $\mathrm{E}^{9}$ are vicinal to the respective methine carbons of $\mathrm{C}^{2}$ and $\mathrm{E}^{7}$. While the methylene carbons of $\mathrm{C}^{3}$ and $\mathrm{E}^{8}$ are vicinal to the respective quaternary carbons of $\mathrm{C}^{1}$ and $\mathrm{E}^{6}$. The methine carbons of $\mathrm{C}^{2}$ and $\mathrm{E}^{7}$ has greater electron density than the quaternary carbons of $\mathrm{C}^{1}$ and $\mathrm{E}^{6}$ and therefore are more shielded causing the methylene carbons of $\mathrm{C}^{4}$ and $\mathrm{E}^{9}$ to be located in the upfield region compared to the methylene carbons of $\mathrm{C}^{3}$ and $\mathrm{E}^{8}$. 
Figure 2. (a) ${ }^{1} \mathrm{H}$ and (b) ${ }^{13} \mathrm{C}-\mathrm{NMR}$ spectra of purified ENR-50 (in $\mathrm{CDCl}_{3}$ ).

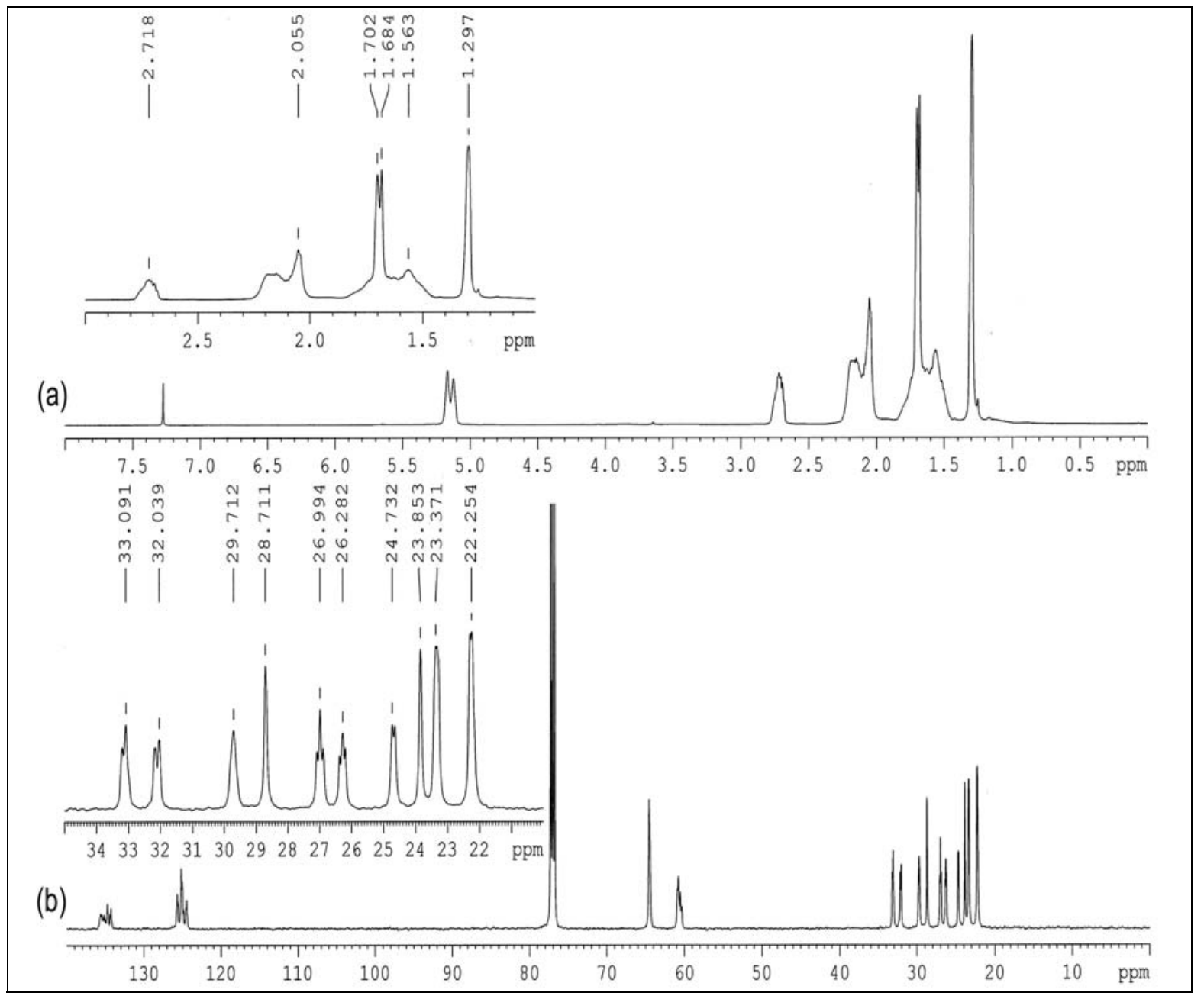

Figure 3. JRES spectra of purified ENR-50 (in $\left.\mathrm{CDCl}_{3}\right)$.

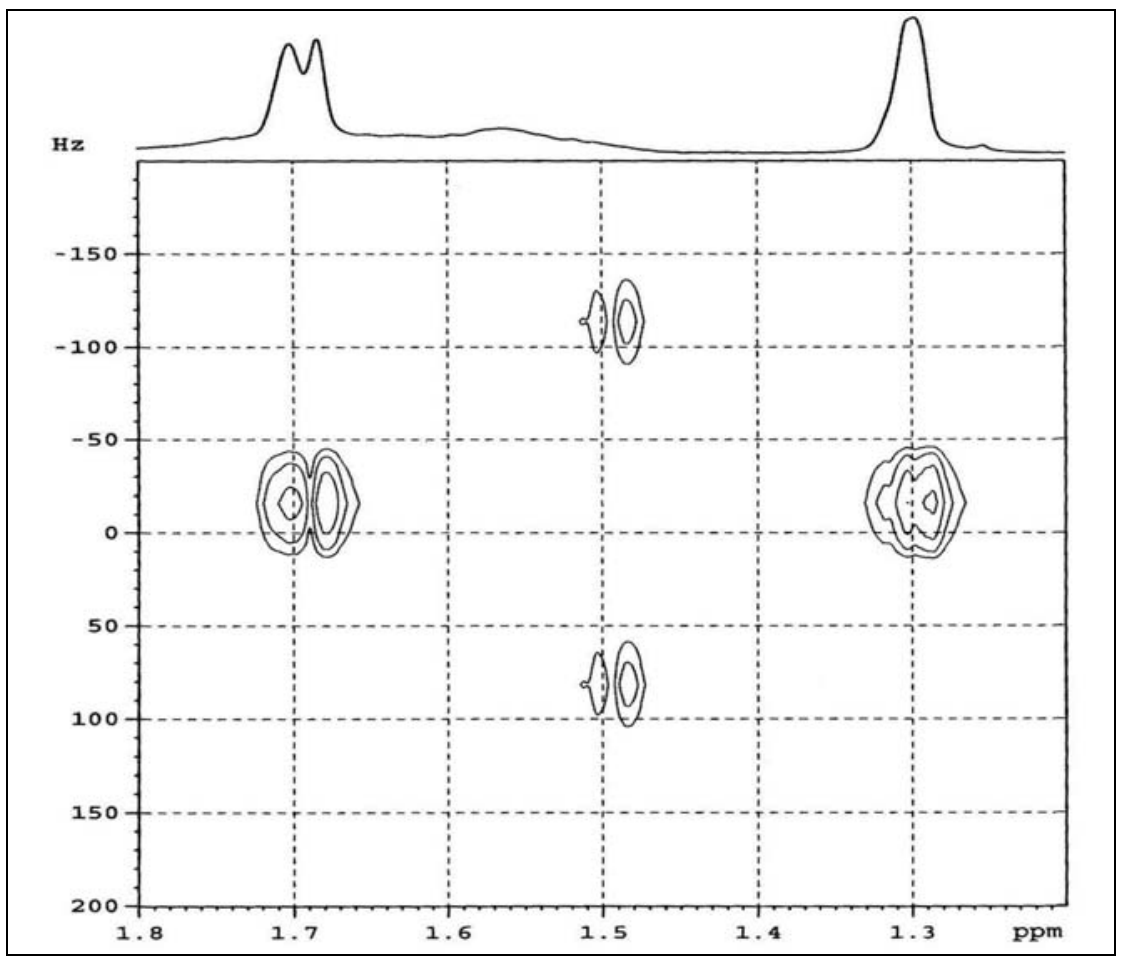


The ${ }^{13} \mathrm{C}$-NMR chemical shifts of the methylene carbons of $\mathrm{C}^{4}$ and $\mathrm{E}^{9}$ are also dependent on their vicinal neighboring units (i.e., to the right (R)- or left (L)-hand side) in the triad. If $\mathrm{E}$ unit is on the $\mathrm{R}$ side of either $\mathrm{C}^{4}$ or $\mathrm{E}^{9}$, the chemical shift is more shielded and upfield than those with neighboring $\mathrm{C}$ unit on the same $\mathrm{R}$ side. Thus the chemical shifts of $\mathrm{CC}^{4} \mathrm{E}, \mathrm{EC}^{4} \mathrm{E}, \mathrm{CE}^{9} \mathrm{E}$ and $\mathrm{E}^{9}$ triads will be upfield compared to $\mathrm{C}^{4}, \mathrm{EC}^{4} \mathrm{C}, \mathrm{CE}^{9} \mathrm{C}$ and $\mathrm{EE}^{9} \mathrm{C}$ triads. Similarly, when $\mathrm{E}$ is on the $\mathrm{L}$ side of $\mathrm{C}^{3}$ and $\mathrm{E}^{8}$ unit in the triad sequence, the chemical shifts of $\mathrm{EC}^{3} \mathrm{C}, \mathrm{EC}^{3} \mathrm{E}, \mathrm{EE}^{8} \mathrm{C}$ and $\mathrm{E}^{8}$ triads will be upfield compared to $\mathrm{C}$ when it is on the $\mathrm{L}$ side of $\mathrm{C}^{3}$ and $\mathrm{E}^{8}$ as in $\mathrm{C}^{3}, \mathrm{CC}^{3} \mathrm{E}, \mathrm{CE}^{8} \mathrm{C}$ and $\mathrm{CE}^{8} \mathrm{E}$ triads. In the case of $\mathrm{C}^{1}, \mathrm{C}^{2}$, $\mathrm{C}^{5}, \mathrm{E}^{6}, \mathrm{E}^{7}$ and $\mathrm{E}^{10}$ triads, the ${ }^{13} \mathrm{C}-\mathrm{NMR}$ chemical shifts of the $\mathrm{E}$ series are located in the upfield region while of the $\mathrm{C}$ series are located in the downfield region. This is due to the double bond in the latter causes deshielding.

\subsubsection{HMQC}

Figure 4 shows the HMQC spectra of purified ENR-50 and the identified triad assignments are tabulated in Table 1 (6th column). HMQC correlates the chemical shift of proton(s) directly bonded to carbon. The ${ }^{1} \mathrm{H}-\mathrm{NMR}$ chemical shift depends on the type of carbon it is attached to. The $\sigma$ bond formed between the carbon and a proton produce shielding effect [27]. Thus depending on the number of $\mathrm{C}-\mathrm{H}$ bond, protons attached to the primary carbon is shifted more upfield compared to the secondary and tertiary carbons.

Figure 4. HMQC spectra of (a) purified ENR-50 and (b) enlargement of the boxed region in (a).

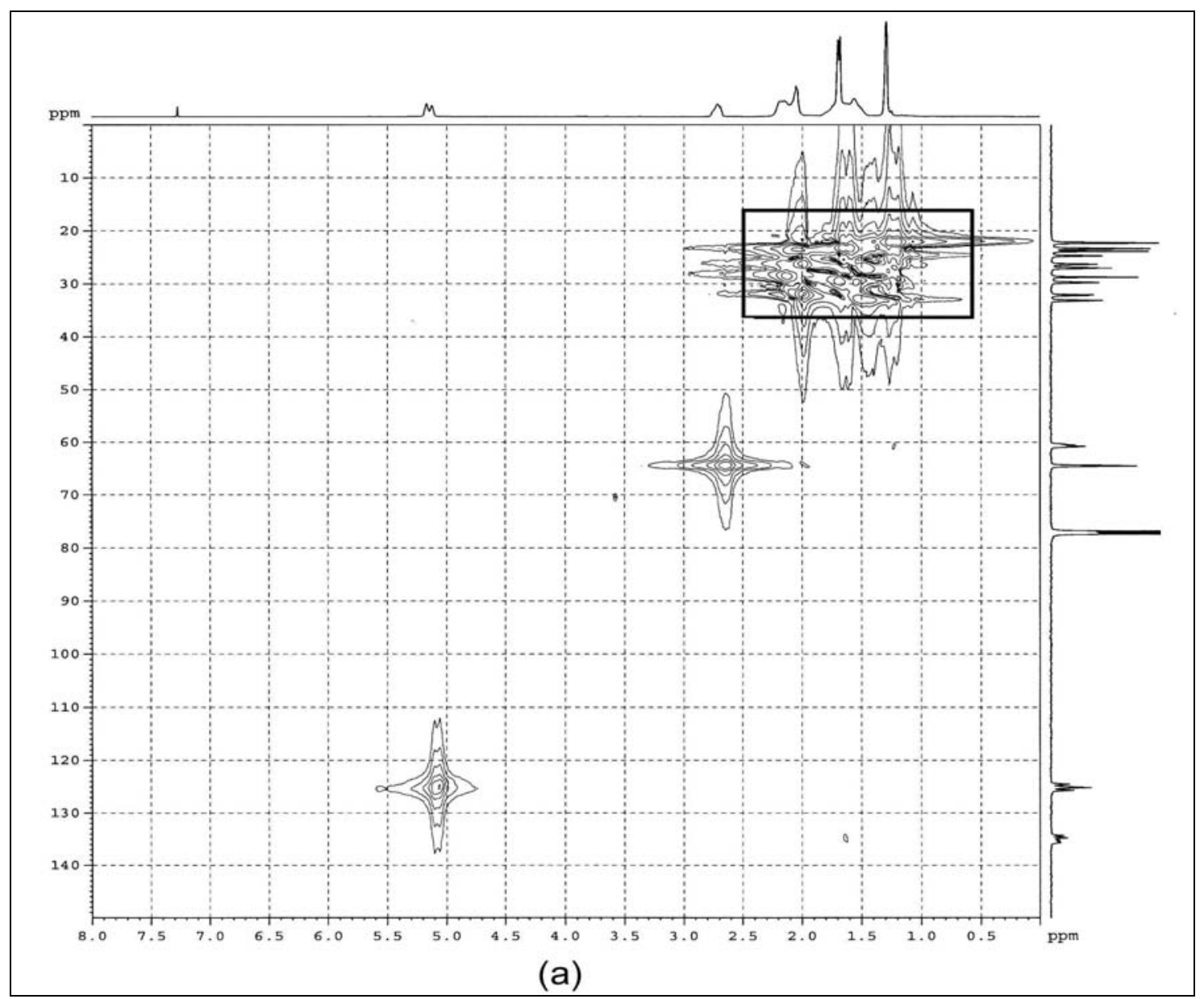


Figure 4. Cont.

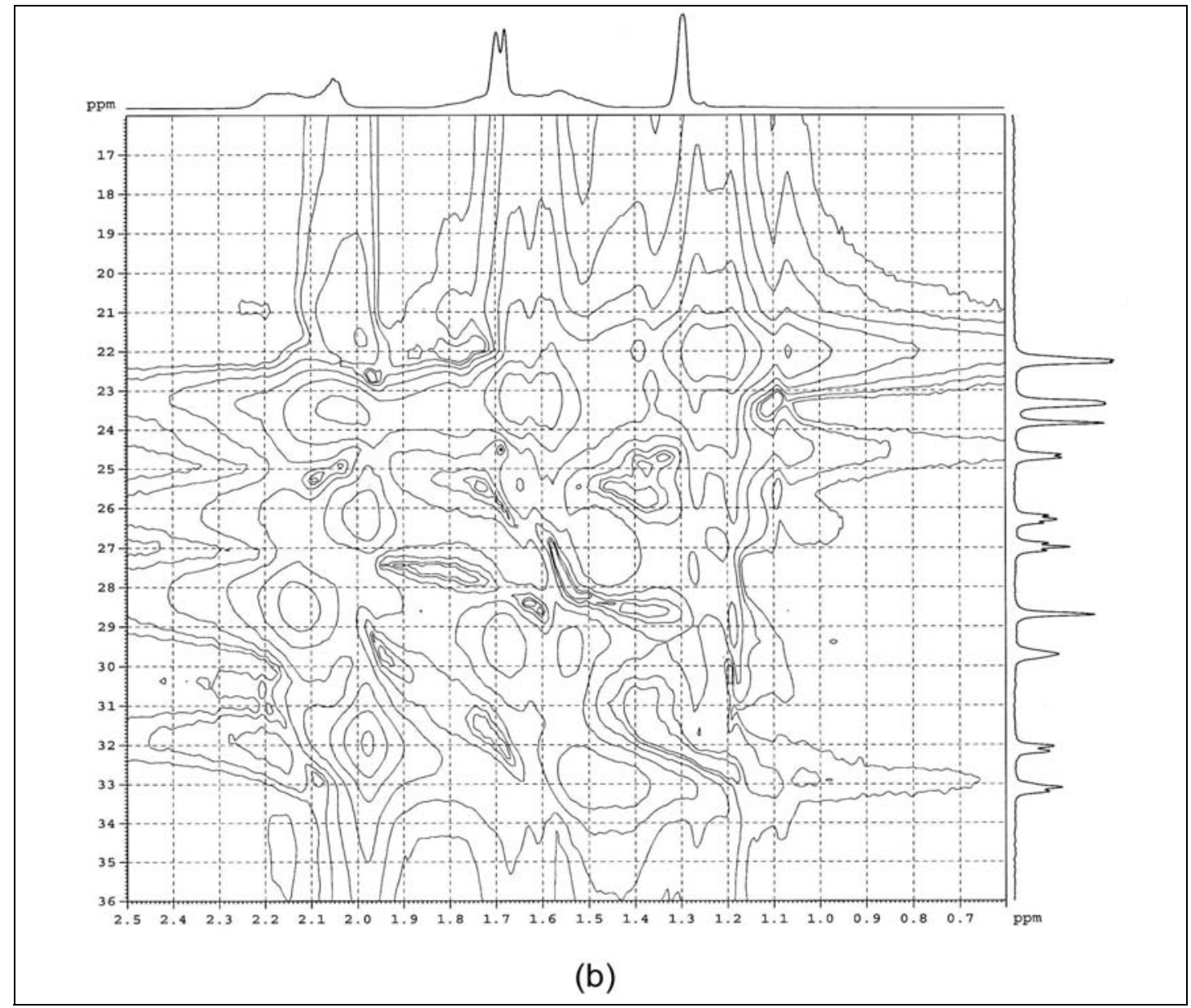

The correlations of the methyls of $\mathrm{E}^{10}$ and $\mathrm{C}^{5}$ are located upfield than the methylenes of $\mathrm{C}^{3}, \mathrm{C}^{4}, \mathrm{E}^{8}$, $E^{9}$ and methines of $C^{2}$ and $E^{7}$. The correlations arising from the methyls of $E^{10}$ and $C^{5}$ also depend on the types of vicinal quartenary carbon, i.e., the epoxide $\left(\mathrm{E}^{6}\right)$ or the double bond $\left(\mathrm{C}^{1}\right)$. The methyl of $\mathrm{E}^{10}$ is vicinal to the quartenary carbon of $E^{6}$ while the methyl of $C^{5}$ is vicinal to quartenary carbon of $\mathrm{C}^{1}$. Thus the methyl of $\mathrm{E}^{10}$ is located upfield than that of methyl of $\mathrm{C}^{5}$. Similarly, the correlations of methines of $E^{7}$ and $C^{2}$ are influenced by the proximity of the epoxide or the double bond. The methine of $\mathrm{E}^{7}$ is shielded by electron density of epoxide while the methine of $\mathrm{C}^{2}$ is deshielded by the double bond. The methine of $\mathrm{E}^{7}$ is therefore more upfield than the methine of $\mathrm{C}^{2}$. In the case of methines of $\mathrm{E}^{7}$ and $C^{2}$, their correlations are located downfield relative to the methylenes of $C^{3}, C^{4}, E^{8}$ and $E^{9}$. The deshielding effects of the double bond caused the correlations of methylenes of $\mathrm{C}^{3}$ and $\mathrm{C}^{4}$ to be located downfield than the respective methylenes of $\mathrm{E}^{8}$ and $\mathrm{E}^{9}$. Therefore $\mathrm{C}^{3}$ is also downfield than $\mathrm{E}^{8}$ while, $\mathrm{C}^{4}$ is downfield than $\mathrm{E}^{9}$.

For the $\mathrm{EC}^{3} \mathrm{C}$ and $\mathrm{EC}^{3} \mathrm{E}$ triads, these correlations are located downfield than $\mathrm{CC}^{4} \mathrm{E}$ and $\mathrm{EC}^{4} \mathrm{E}$ in the ${ }^{13} \mathrm{C}-\mathrm{NMR}$ spectrum. However, in the ${ }^{1} \mathrm{H}-\mathrm{NMR}$ spectrum, both appeared as overlapped peak. This is because the correlations of $\mathrm{C}^{3}$ and $\mathrm{C}^{4}$ superimpose those of $\mathrm{CC}^{3} \mathrm{E}$ and $\mathrm{EC}^{4} \mathrm{C}$ triads. Thus it can be similarly argued that the correlations of the triads $\mathrm{CE}^{8} \mathrm{C}$ and $\mathrm{CE}^{8} \mathrm{E}$ occur downfield than $\mathrm{CE}{ }^{9} \mathrm{C}$, and $\mathrm{EE}^{9} \mathrm{C}$ in the ${ }^{13} \mathrm{C}$-NMR spectrum while in the ${ }^{1} \mathrm{H}-\mathrm{NMR}$ spectrum, those of $\mathrm{EE}^{8} \mathrm{C}$ and $\mathrm{CE}{ }^{9} \mathrm{E}$ superimpose those of $E^{8}$ and $E^{9}$. 


\subsubsection{HMBC}

The HMQC results were further scrutinized using HMBC analysis. The HMBC correlation spectra of purified ENR-50 are shown in Figure 5. The ${ }^{1} \mathrm{H}-{ }^{13} \mathrm{C}$ signals correlations are tabulated in Table 1 (7th and 8th column). The overlapping proton signals at $\delta 1.56,1.68-1.70,2.06$ and 2.15-2.19 ppm were individually assigned through coupling correlations. The coupling correlation between neighboring units classifies and arranges the methylene carbons in the correct triad sequence thus confirmed the previous HMQC assignments. The methyls of $E^{10}$ and $C^{5}$, and methines of $E^{7}$ and $C^{2}$ were affirmatively assigned based on the deduced correlations and consistent with the previous study [11].

\subsubsection{COSY}

The COSY of purified ENR-50 is shown in Figure 6 and was conducted to evaluate the representations of ${ }^{1} \mathrm{H}-\mathrm{NMR}$ signals at $\delta 1.56,1.68-1.70,2.06$ and $2.15-2.19 \mathrm{ppm}$. The spin coupling correlations of the signals and the assigned triad sequences are as tabulated in column 9th and 10th in Table 1.

The signal at $\delta 1.56$ ppm correlates with the signals at $\delta 2.72,2.15-2.19$ and $1.68-1.70 \mathrm{ppm}$. The signal of $\mathrm{E}^{7}$ methine proton at $\delta 2.72 \mathrm{ppm}$ correlates to the methylene protons of the middle unit of the triad sequences of $\mathrm{CE}^{9} \mathrm{C}$ and $\mathrm{EE}^{9} \mathrm{C}$. The signal representing the methylene protons of $\mathrm{CC}^{4} \mathrm{E}$ and $\mathrm{EC}^{4} \mathrm{E}$ as well as $\mathrm{EC}^{3} \mathrm{C}$ and $\mathrm{EC}^{3} \mathrm{E}$ at $\delta 2.15-2.19 \mathrm{ppm}$ correlates to the methylene protons of isoprene $\mathrm{CE}^{8} \mathrm{C}$, $\mathrm{CE}^{8} \mathrm{E}, \mathrm{CE}^{9} \mathrm{C}$ and $\mathrm{EE}^{9} \mathrm{C}$. While the signal assigned to the methyl protons of $\mathrm{C}^{5}$, methylene protons of $\mathrm{CE}^{9} \mathrm{E}$ and $\mathrm{E}^{9}$ at $\delta 1.68-1.70 \mathrm{ppm}$ correlates to methylene protons of the epoxidized isoprene of $\mathrm{EE}^{8} \mathrm{C}$ and $\mathrm{E}^{8}$. The methyl proton of $\mathrm{E}^{10}$ at $\delta 1.30 \mathrm{ppm}$ does not show any correlation as it is attached to the quartenary carbon, $\mathrm{E}^{6}$.

The signal that represents the methylene protons of the middle unit of $\mathrm{C}^{4}$ and $\mathrm{EC}^{4} \mathrm{C}$ as well as $\mathrm{C}^{3}$ and $\mathrm{CC}^{3} \mathrm{E}$ at $\delta 2.06 \mathrm{ppm}$ correlates with the signals at $\delta 2.06$ and 5.12-5.17 ppm. All these methylene protons are correlated to the methylene protons of isoprene with the same unit of triad at $\delta 2.06 \mathrm{ppm}$. However, for the triads $\mathrm{C}^{4}$ and $\mathrm{EC}^{4} \mathrm{C}$, the correlation is to the methine proton of isoprene $\mathrm{C}^{2}$ at $\delta 5.12-5.17 \mathrm{ppm}$.

The methylene protons of $\mathrm{CC}^{4} \mathrm{E}$ and $\mathrm{EC}^{4} \mathrm{E}$ at $\delta 2.15-2.19 \mathrm{ppm}$ were correlated with the signals at $\delta$ $5.12-5.17$ and $1.56 \mathrm{ppm}$. These are due to the methine proton of $\mathrm{C}^{2}(\delta 5.12-5.17 \mathrm{ppm})$ and the neighbouring methylene protons of epoxidized isoprene $(\delta 1.56 \mathrm{ppm})$ within the same unit. The methylene protons of $\mathrm{EC}^{3} \mathrm{C}$ and $\mathrm{EC}^{3} \mathrm{E}$ at $\delta 2.15-2.19 \mathrm{ppm}$ are also correlated to the neighbouring methylene protons of epoxidized isoprene $(\delta 1.56 \mathrm{ppm})$ within the same unit of triad sequence.

Based on the COSY of purified ENR-50, the signal at $\delta 1.56 \mathrm{ppm}$ represents the methylene protons of $\mathrm{CE}^{9} \mathrm{C}, \mathrm{EE}^{9} \mathrm{C}, \mathrm{E}^{8}, \mathrm{EE}^{8} \mathrm{C}, \mathrm{CE}^{8} \mathrm{C}$ and $\mathrm{CE}^{8} \mathrm{E}$. The signal at $\delta 1.68-1.70$ ppm represents the methyl protons of $\mathrm{C}^{5}$ and the methylene protons of $\mathrm{CE}^{9} \mathrm{E}$ and $\mathrm{E}^{9}$. The signal at $\delta 2.06 \mathrm{ppm}$ arises from the methylene protons of $\mathrm{C}^{4}, \mathrm{EC}^{4} \mathrm{C}, \mathrm{C}^{3}$ and $\mathrm{CC}^{3} \mathrm{E}$, while the signal at $\delta$ 2.15-2.19 ppm represents the methylene protons of $\mathrm{CC}^{4} \mathrm{E}, \mathrm{EC}{ }^{4} \mathrm{E}, \mathrm{EC}^{3} \mathrm{C}$ and $\mathrm{EC}^{3} \mathrm{E}$. These conformed to the HMQC results above. 
Figure 5. HMBC spectra of (a) purified ENR-50 and (b) enlargement of the boxed region in (a).

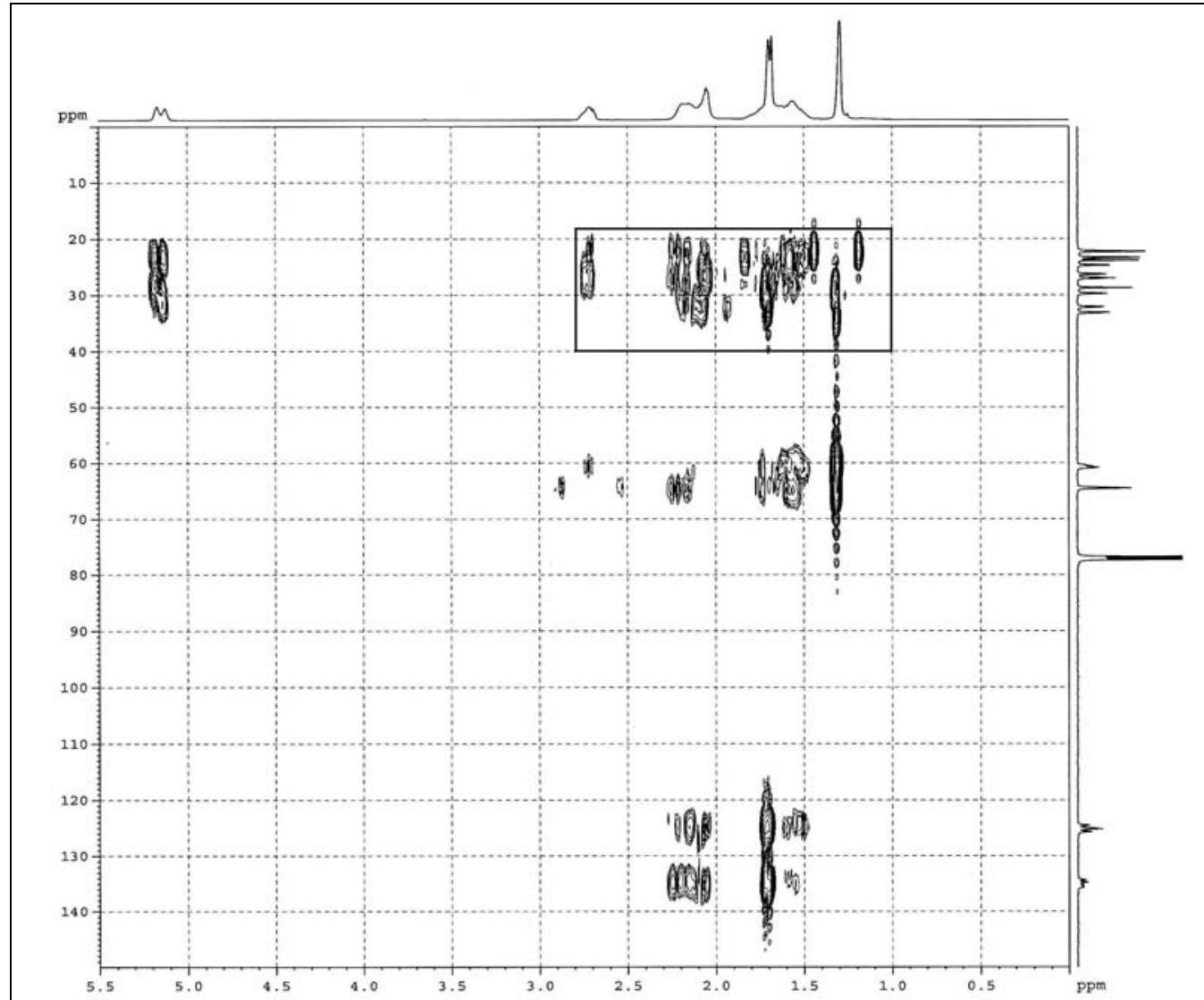

(a)

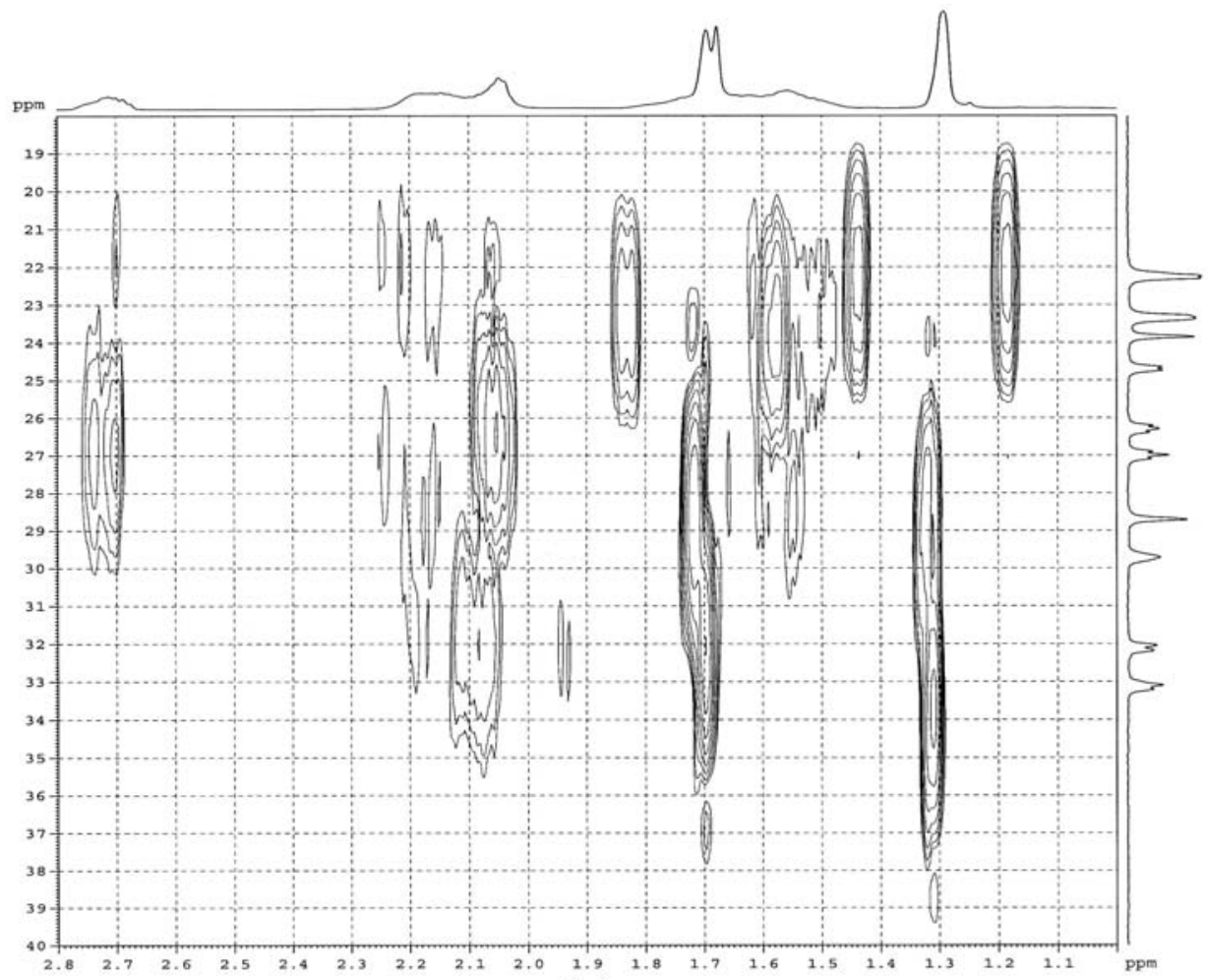

(b) 
Figure 6. COSY spectra of purified ENR-50.

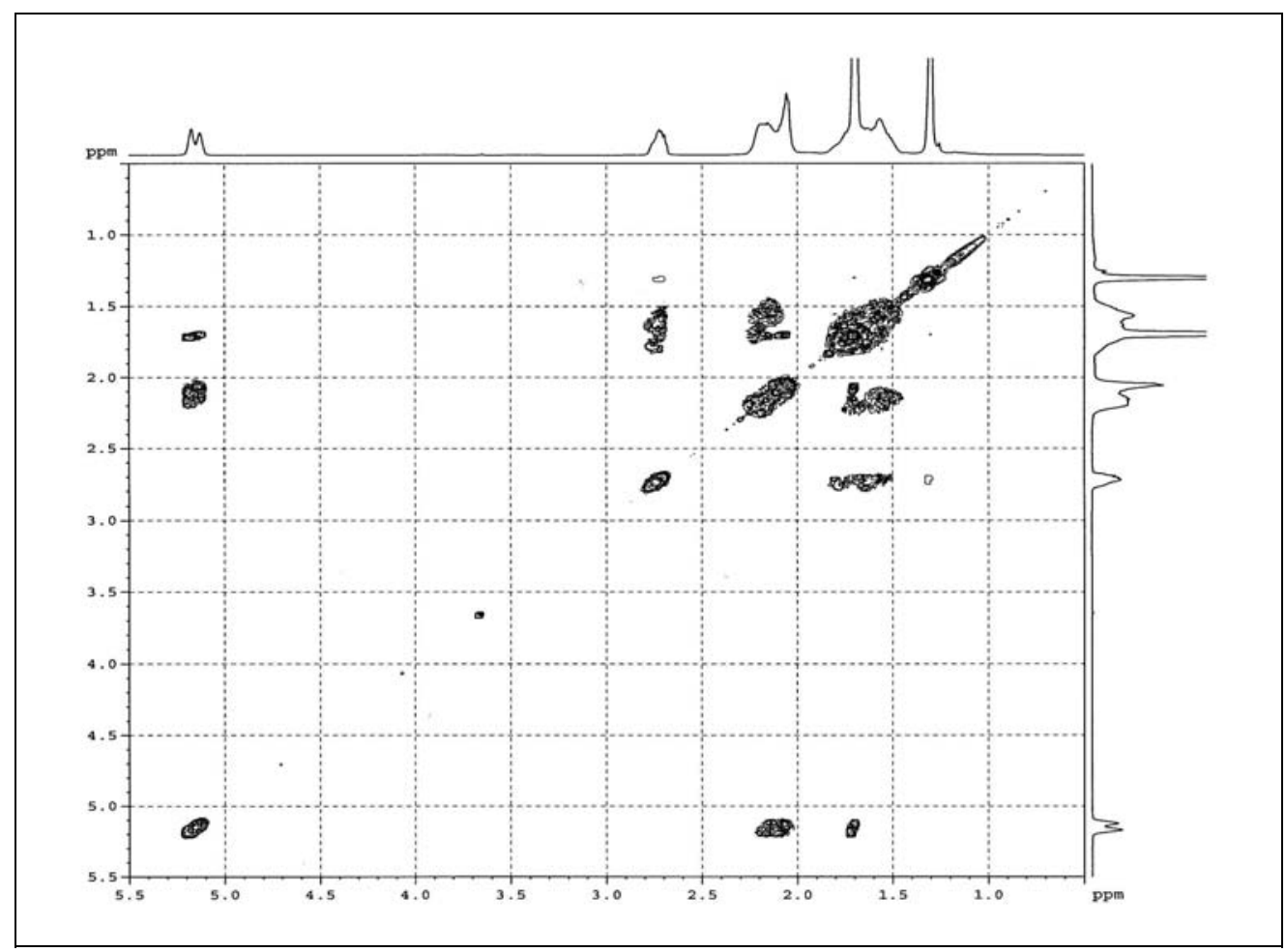

\subsection{Cyclic Dithiocarbonate Derivative of ENR-50}

The reaction of $\mathrm{CS}_{2}$ with purified ENR-50 afforded the five-membered ring dithiocarbonate derivative of ENR-50 as shown in Scheme 2. The formation of cyclic dithiocarbonate is generally a Diels-Alder type of reaction [24]. In this work, a very dilute solution of purified ENR-50 was used with the aim to stretch the random coil conformation of ENR-50 polymer chains in order to expose the reactive epoxidized isoprene unit using dimethylaminopyridine (DMAP) as the catalyst. The $\mathrm{C}-\mathrm{S}$ moiety of $\mathrm{CS}_{2}$ is inserted into the epoxidized isoprene of the ENR-50. The reaction probably occurs via the $\mathrm{S}_{\mathrm{N}} 2$ mechanism that involved the epoxide ring opening.

\subsubsection{FTIR Spectroscopy}

Comparison of the FTIR spectrum of purified ENR-50 (Figure 7a) with the FTIR spectrum of the reaction product (Figure $7 \mathrm{~b}$ ) revealed two new bands at 1096 and $1060 \mathrm{~cm}^{-1}$ that are assigned to $\mathrm{C}=\mathrm{S}$ and C-O functionalities, respectively $[28,29]$. The latter $\left(v_{\mathrm{C}-\mathrm{O}}\right)$ is located at lower wavenumber than the $v_{\mathrm{C}-\mathrm{O}-\mathrm{C}}$ for cyclic ether at $1150-1070 \mathrm{~cm}^{-1}$. The weak C-S stretching vibration in the range of $700-590 \mathrm{~cm}^{-1}$ indicates bonding between sulfur from $\mathrm{CS}_{2}$ and the carbon $\mathrm{E}^{7}$ [29]. The band attributed to the epoxide is shifted to higher wavenumber compared to purified ENR-50, i.e., from 875 to $892 \mathrm{~cm}^{-1}$. Other typical bands of $\mathrm{C}=\mathrm{C}$ and $\mathrm{C}-\mathrm{H}$ are also slightly shifted to a low wavenumber region. This is probably due to the intermittent presence of cyclic dithiocarbonate within the ENR-50 chains. 
Figure 7. FTIR spectra of (a) purified ENR-50 and (b) cyclic dithiocarbonate derivative of ENR-50.

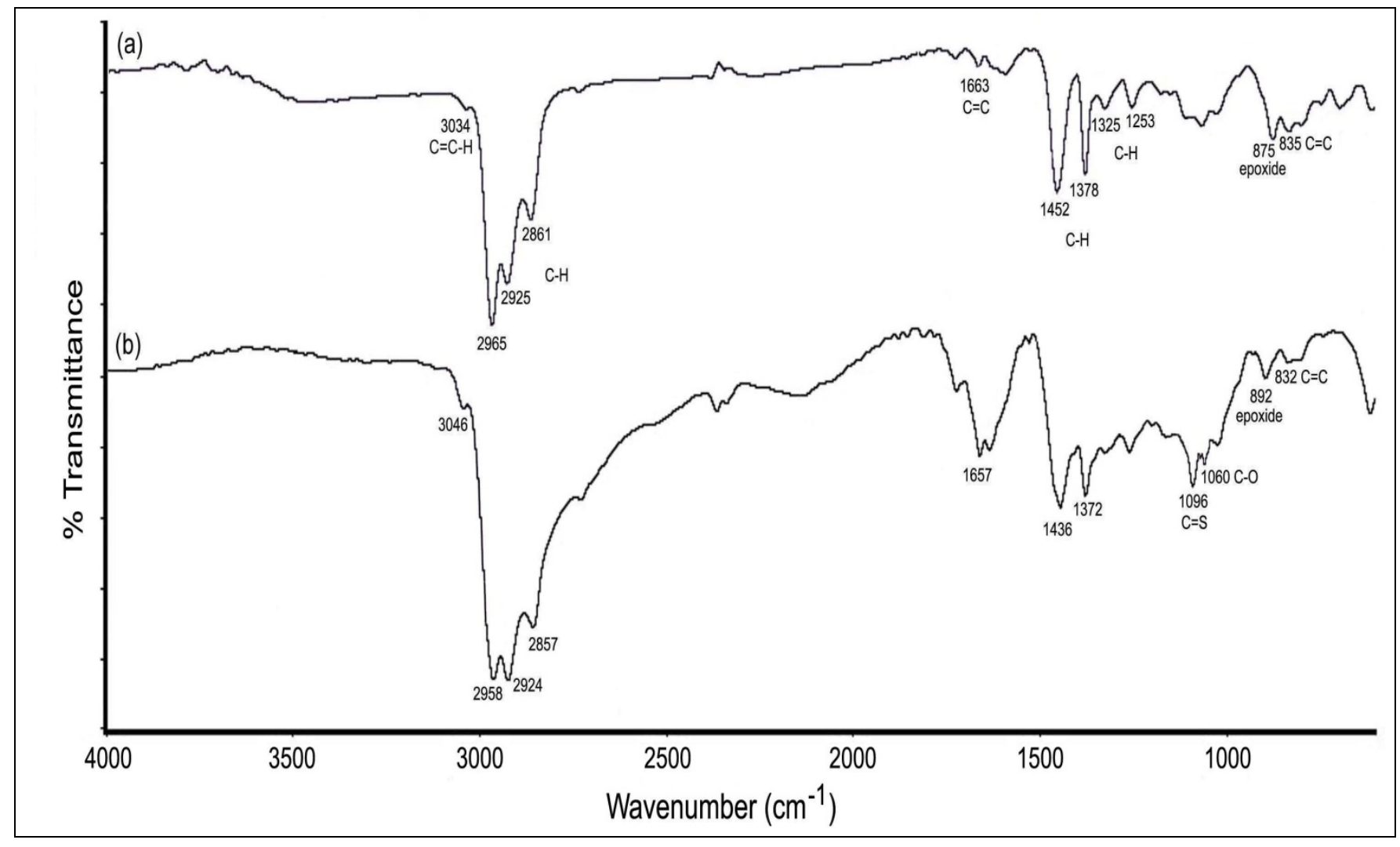

Comparison of the spectra of Figure $7 \mathrm{a}, \mathrm{b}$ also indicates that there is a reduction in the epoxide band intensity after the reaction. The extent of dithiocarbonation reaction was estimated using semiquantitative FTIR approach. This was based on the band area of the methyl, $\mathrm{C}=\mathrm{S}$ and the epoxide functionalities before and after dithiocarbonation reaction. The band due to methyl at $1378-1372 \mathrm{~cm}^{-1}$ was used as the internal standard in this work [8]. Based on the FTIR approach, the percentage of epoxidation in the purified ENR-50 is $\sim 50.7 \%$. It was also found that after the dithiocarbonation reaction, $47.9 \%$ of the epoxide has reacted with $\mathrm{CS}_{2}$ while $52.1 \%$ were unreacted.

\subsection{2. ${ }^{1} \mathrm{H}$ and ${ }^{13} \mathrm{C}-\mathrm{NMR}$ Spectroscopy}

The ${ }^{1} \mathrm{H}$ and ${ }^{13} \mathrm{C}-\mathrm{NMR}$ spectra of cyclic dithiocarbonate derivative of ENR-50 are shown in Figure 8. The chemical shifts of the cyclic dithiocarbonate derivative of ENR-50 as well as the triad and carbon assignments are given in Table 2 . From Figure $8 \mathrm{a}$, with the exception for the splitting of peak at $\delta$ 1.58-1.63 ppm, the ${ }^{1} \mathrm{H}-\mathrm{NMR}$ spectrum shows almost similar features compared to purified ENR-50 (Figure 2a). As discussed earlier, the split peak above represents the methylene protons of $\mathrm{EE}^{8} \mathrm{C}, \mathrm{E}^{8}$, $\mathrm{CE}^{8} \mathrm{C}, \mathrm{CE}^{8} \mathrm{E}, \mathrm{CE}^{9} \mathrm{C}$ and $\mathrm{EE}^{9} \mathrm{C}$ triads. The formation of cyclic five-membered dithiocarbonate within the ENR chain involves the $\mathrm{E}^{6}$ and $\mathrm{E}^{7}$ carbons as illustrated in Scheme 2. This, in turn, has affected the environment of $\mathrm{E}^{8}$ and $\mathrm{E}^{9}$ carbons. Therefore the split peaks observed at $\delta 1.58-1.63 \mathrm{ppm}$ may be attributed to the methylene protons attached to the five-membered (cylic dithiocarbonate) and three-membered (oxirane) rings, respectively. The methylene protons attached to the five-membered ring are slightly downfield at $\delta 1.63 \mathrm{ppm}$ compared to those attached to the three-membered ring (at $\delta 1.58 \mathrm{ppm}$ ). 
Figure 8. (a) ${ }^{1} \mathrm{H}$ and (b) ${ }^{13} \mathrm{C}$-NMR spectra of cyclic dithiocarbonate derivative of ENR-50 (in $\mathrm{CDCl}_{3}$ ).

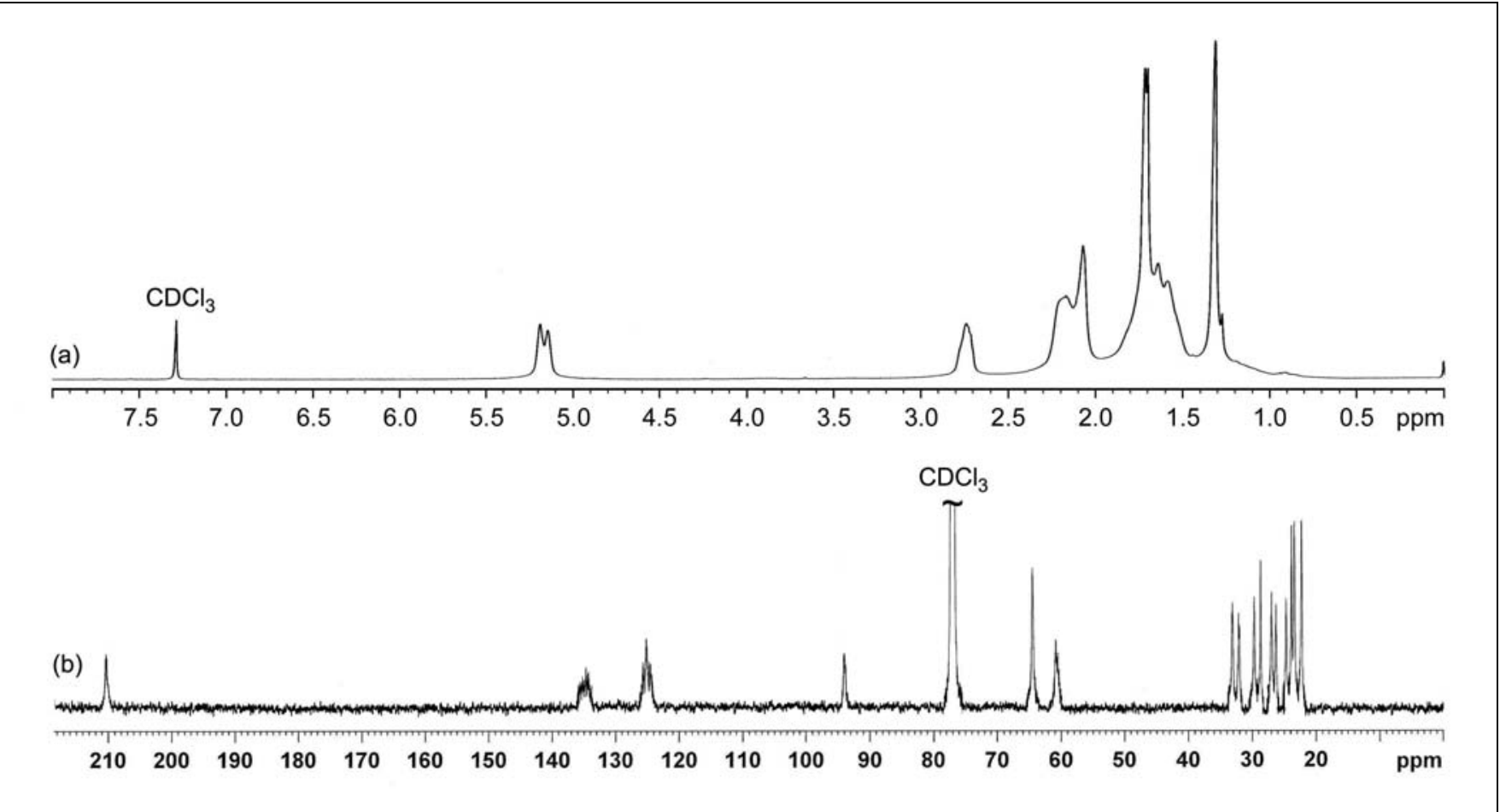

Table 2. ${ }^{1} \mathrm{H}$ and ${ }^{13} \mathrm{C}-\mathrm{NMR}$ chemical shifts and triad assignments for purified ENR-50 and its cyclic dithiocarbonate derivative.

\begin{tabular}{|c|c|c|c|c|}
\hline \multicolumn{4}{|c|}{ Chemical shift $\delta(\mathrm{ppm})$} & \multirow[t]{3}{*}{ Triad assignment } \\
\hline \multicolumn{2}{|r|}{${ }^{1} \mathbf{H}$} & \multicolumn{2}{|r|}{${ }^{13} \mathrm{C}$} & \\
\hline ENR-50* & $\begin{array}{c}\text { Cyclic dithiocarbonate } \\
\text { derivative }\end{array}$ & ENR-50 * & $\begin{array}{c}\text { Cyclic dithiocarbonate } \\
\text { derivative }\end{array}$ & \\
\hline 1.30 & 1.31 & 22.3 & 22.4 & $\mathrm{E}^{10}$ \\
\hline 1.56 & $1.58-1.63$ & $\begin{array}{l}29.7 \\
33.1 \\
27.0 \\
\end{array}$ & $\begin{array}{l}29.8 \\
33.1 \\
27.0 \\
\end{array}$ & $\begin{array}{l}\mathrm{EE}^{8} \mathrm{C}, \mathrm{E}^{8} \\
\mathrm{CE}^{8} \mathrm{C}, \mathrm{CE}^{8} \mathrm{E} \\
\mathrm{CE} \mathrm{E}^{9} \mathrm{C}, \mathrm{EE}^{9} \mathrm{C}\end{array}$ \\
\hline $1.68-1.70$ & $1.70-1.71$ & $\begin{array}{l}23.4 \\
24.7 \\
\end{array}$ & $\begin{array}{l}23.5 \\
24.8 \\
\end{array}$ & $\begin{array}{l}\mathrm{C}^{5} \\
\mathrm{CE}^{9} \mathrm{E}, \mathrm{E}^{9}\end{array}$ \\
\hline 2.06 & 2.08 & $\begin{array}{l}26.3 \\
32.0 \\
\end{array}$ & $\begin{array}{l}26.4 \\
32.2 \\
\end{array}$ & $\begin{array}{l}\mathrm{C}^{4}, \mathrm{EC}^{4} \mathrm{C} \\
\mathrm{C}^{3}, \mathrm{CC}^{3} \mathrm{E}\end{array}$ \\
\hline $2.15-2.19$ & $2.12-2.19$ & $\begin{array}{l}23.9 \\
28.7\end{array}$ & $\begin{array}{l}24.0 \\
28.7\end{array}$ & $\begin{array}{l}\mathrm{CC}^{4} \mathrm{E}, \mathrm{EC}^{4} \mathrm{E} \\
\mathrm{EC}^{3} \mathrm{C}, \mathrm{EC}^{3} \mathrm{E}\end{array}$ \\
\hline- & - & 60.7 & 61.0 & $\mathrm{E}^{6}$ \\
\hline 2.72 & 2.73 & 64.5 & 64.8 & $\mathrm{E}^{7}, \mathrm{E}^{7}$ of five-membered ring \\
\hline- & - & - & 94.0 & $\mathrm{E}^{6}$ of five-membered ring \\
\hline $5.12-5.17$ & $5.15-5.19$ & 125.0 & 125.1 & $\mathrm{C}^{2}$ \\
\hline- & - & 134.7 & 134.9 & $\mathrm{C}^{1}$ \\
\hline- & - & - & 210.5 & $\mathrm{CS}_{2}$ carbon of five-membered ring \\
\hline
\end{tabular}

* from Table 1 . 
These methylene protons shows equal proton integrals compared to purified ENR-50. This is confirmed by the previous FTIR results where, approximately 1:1 ratio of reacted and unreacted epoxide is observed after the dithiocarbonation reaction. The formation of cyclic dithiocarbonate within the ENR chain however, does not produce any new peaks or change in the chemical shifts. Therefore it is expected that the ENR-50 polymer chains conformation was maintained upon dithiocarbonation.

The formation of cyclic dithiocarbonate also gives two new ${ }^{13} \mathrm{C}-\mathrm{NMR}$ peaks at $\delta 210.5$ and $94.0 \mathrm{ppm}$, respectively [24]. The peak at $\delta 210.5 \mathrm{ppm}$ represents the carbon of $>\mathrm{C}=\mathrm{S}$ of the five-membered ring and is located at the most downfield region as this carbon is simultaneously bonded to the electronegative oxygen and sulfur. The carbon $\mathrm{E}^{6}$ of the five-membered ring is located slightly downfield at $\delta 94.0 \mathrm{ppm}$ because it is vicinally bonded to the carbon of $>\mathrm{C}=\mathrm{S}$. The chemical shift for carbon $\mathrm{E}^{7}$ of the five-membered ring and the carbons of $\mathrm{E}^{6}$ and $\mathrm{E}^{7}$ of the three-membered ring (oxirane) however, remains unchanged, i.e., similar to the purified ENR-50. The main difference between the cyclic dithiocarbonated ENR reported in this work and the previously reported cyclic carbonated NR [30] is the position of $\mathrm{S}$ atom in the former is replaced by $\mathrm{O}$ atom in the latter. This gives rise to the different chemical shifts due to the different in electronegativity of $\mathrm{S}$ and $\mathrm{O}$ atoms. In the cyclic carbonated NR, the ${ }^{13} \mathrm{C}$-NMR chemical shift of quartenary carbon of $>\mathrm{C}=\mathrm{O}$ is at $\delta 151.0 \mathrm{pm}$, the tertiary carbon of $>\mathrm{C}(\mathrm{H})-\mathrm{O}-$ is at $\delta 75.0 \mathrm{ppm}$, and the quartenary carbon of $\equiv \mathrm{C}-\mathrm{O}-$ is at $\delta 74.0$ ppm, respectively [30].

The ${ }^{13} \mathrm{C}$-NMR quantitative analysis was carried out to evaluate the epoxidation level in the purified ENR-50 as well as its cyclic dithiocarbonate derivative. The epoxidation level in purified ENR-50 was found to be $\sim 51.4 \%$. In the cyclic dithiocarbonate derivative, $52.0 \%$ of the epoxide ring is unreacted while $48.0 \%$ has reacted with $\mathrm{CS}_{2}$. These results are consistent with the FTIR results discussed previously.

Figure 9 shows the various DEPT spectra for cyclic dithiocarbonate derivative of ENR-50. In DEPT-135, the signals of the methylene carbons are shown downward (negative) while the methyl and methine carbons are shown as the upward peaks (positive) [31]. The spectrum for DEPT-90 shows only the methine carbons [31]. However, spectrum for DEPT-45 shows the upward peaks for methyl, methylene and methine carbons. The peak at $\delta 64.8 \mathrm{ppm}$ appears as upward signal in DEPT-135, DEPT-90 and DEPT-45 proved its assignment as a methine carbon for $\mathrm{E}^{7}$ of the three-membered ring (oxirane) as well as carbon $\mathrm{E}^{7}$ of the five-membered ring. DEPT quartenary only shows quartenary carbon as upward peak in the spectrum. The real signals of the quartenary carbons in this spectrum are at $\delta 60.1,94.0,134.9$ and $210.5 \mathrm{ppm}$. While the rest of the peaks in this spectrum are not reliable because the signal to noise ratio is less than 5 and those peaks are proven previously as methyl, methylene and methine in DEPT-135, -90 and -45 except for the $\mathrm{CDCl}_{3}$ peak which appear at $77.0 \mathrm{ppm}$. Thus the peaks at $\delta 94.0 \mathrm{ppm}$ and $210.5 \mathrm{ppm}$ are assigned for $\mathrm{E}^{6}$ and $\mathrm{CS}_{2}$ carbon of five-membered ring, respectively. 
Figure 9. (a) DEPT-135; (b) DEPT-90; (c) DEPT-45 and (d) DEPT quartenary spectra of cyclic dithiocarbonate derivative of ENR-50 (in $\mathrm{CDCl}_{3}$ ).

(a)

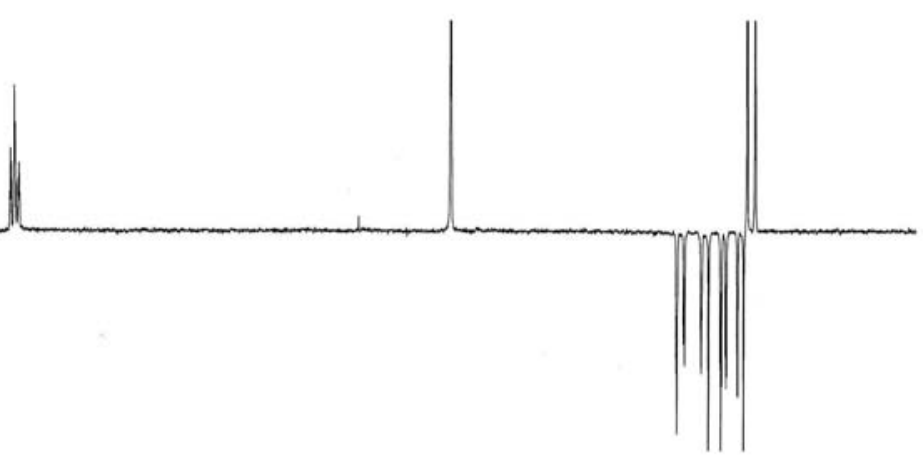

(b)

(c)

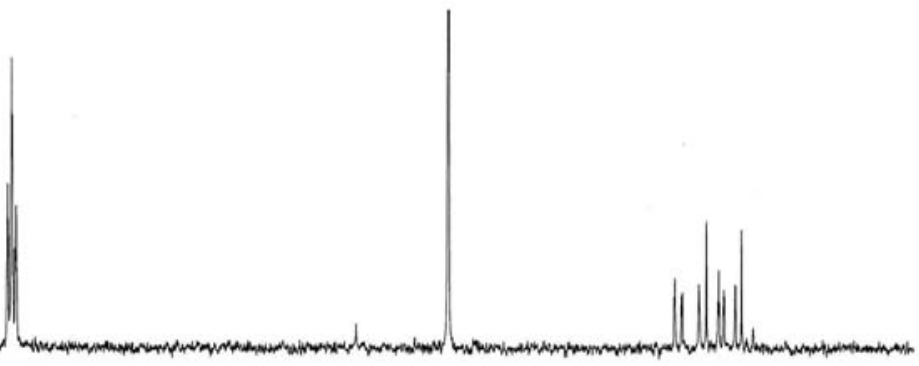

(d)

$220 \begin{array}{llllllllllllllllllllll}210 & 200 & 190 & 180 & 170 & 160 & 150 & 140 & 130 & 120 & 110 & 100 & 90 & 80 & 70 & 60 & 50 & 40 & 30 & 20 & 10 \mathrm{ppm}\end{array}$

2.2.3. Proposed Mechanism for the Formation of Cyclic Dithiocarbonate

A proposed mechanism for the formation of cyclic dithiocarbonate from the reaction of ENR-50 with $\mathrm{CS}_{2}$ is shown in Scheme 3. DMAP catalyst is well known as a strong nucleophile. The lone pair electrons of DMAP attack the carbon of $\mathrm{CS}_{2}$ and form a $\left[\mathrm{S}_{2} \mathrm{C}-\mathrm{DMAP}\right]$ complex. The complex provides the condition for overall reaction to proceed via a $\mathrm{S}_{\mathrm{N}} 2$ mechanism [32]. In this condition, the sulfur-centered nucleophile attacks the less substituted and less sterically hindered carbon $\mathrm{E}^{7}$ and ring opened the oxirane. The bond between oxygen and carbon $\mathrm{E}^{7}$ is severed and produced oxygen-centered nucleophile. This nucleophile attacks the CS carbon of [ENR-S(S)C-DMAP] intermediate with simultaneous detachment of a DMAP molecule and therefore affecting a ring closure via formation of $\mathrm{O}-\mathrm{C}$ bond. The ring closure constitutes formation of cyclic dithiocarbonate derivative of ENR-50. 
Scheme 3. Proposed mechanism for the formation of cyclic dithiocarbonate derivative of ENR-50 via oxirane ring opening.
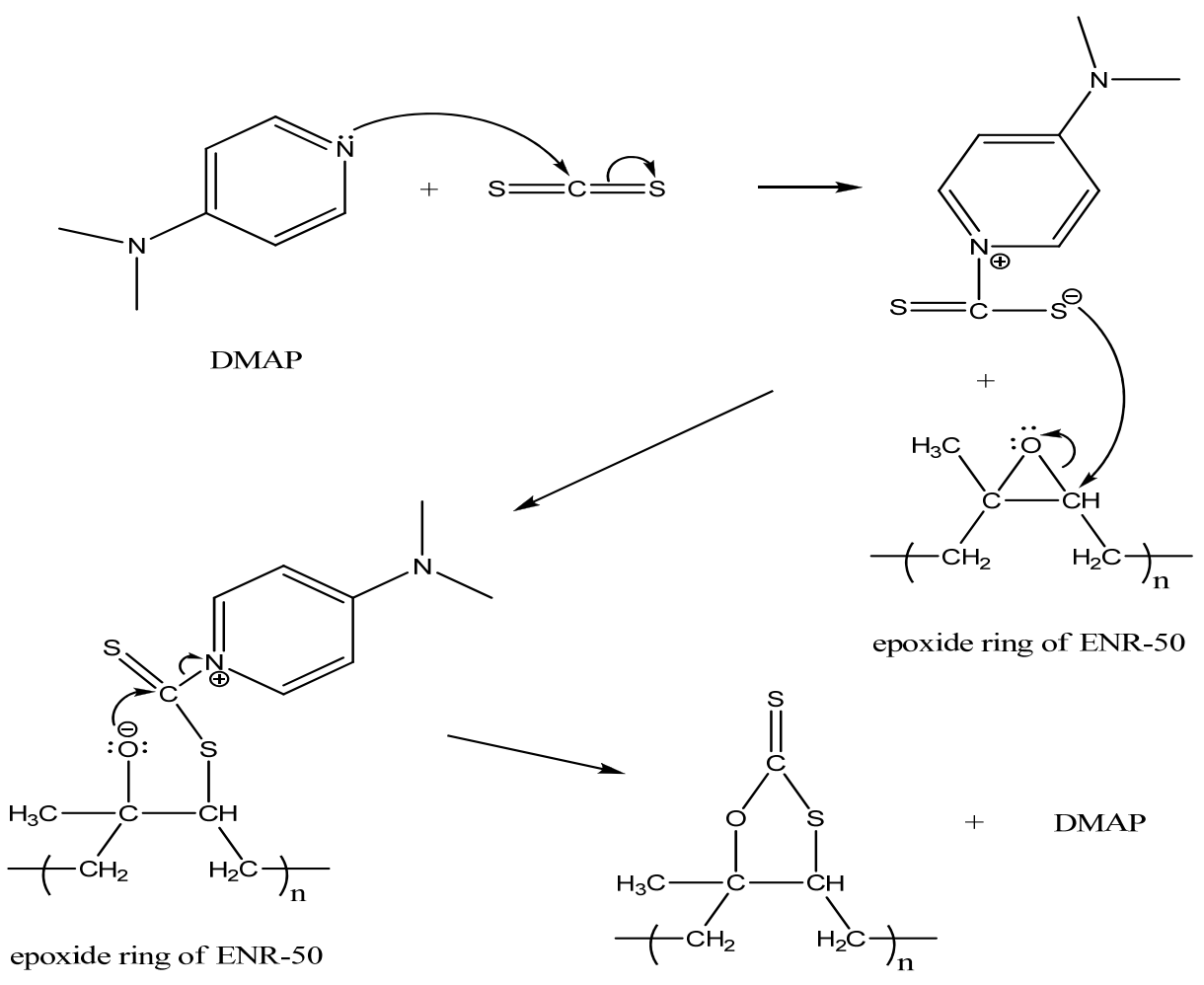

cyclic dithiocarbonate derivative

\section{Experimental}

\subsection{Materials}

Carbon disulfide 99.7\%, $\mathrm{CS}_{2}$ (BDH Chemicals, Poole, UK), 4-dimethylaminopyridine 98\%, DMAP and deuterated chloroform, $\mathrm{CDCl}_{3}$ (Fluka Chemicals, Buchs, Switzerland) and $n$-hexane (Systerm, Selangor, Malaysia) were all obtained commercially and used without further purification unless otherwise stated. Epoxidized natural rubber with 50\% epoxidation (ENR-50) was purchased from the Rubber Research Institute (Kuala Lumpur, Malaysia).

\subsection{Preparative Procedure}

\subsubsection{Purification of ENR-50 [19]}

ENR-50 (about $20.00 \mathrm{~g}$ ) was swelled in chloroform $(400 \mathrm{~mL})$ and stirred for $24 \mathrm{~h}$ at room temperature. The solution was then filtered through cotton gauze to separate the gel (high molecular ENR-50) from the extract (low molecular weight ENR-50). The later was precipitated in $n$-hexane and stirred using a glass rod. The white precipitate stuck to the glass rod was transferred to a Petri dish and was dried in a vacuum oven at $50{ }^{\circ} \mathrm{C}$ for two days. Mass of purified ENR-50 sample was recorded daily until a constant weight was achieved. 


\subsubsection{Reaction of Purified ENR-50 with $\mathrm{CS}_{2}[24]$}

Purified ENR-50 (about $20 \mathrm{mg}, 1.31 \times 10^{-4} \mathrm{~mol}$ ) was swelled in $\mathrm{CS}_{2}\left(40 \mathrm{~mL}, 6.62 \times 10^{-4} \mathrm{~mol}\right.$ ) under constant stirring. DMAP catalyst (about $16.44 \mathrm{mg}, 1.32 \times 10^{-4} \mathrm{~mol}$ ) was added to the stirring solution. The mixture was then refluxed for $3 \mathrm{~h}$ and then left to cool to room temperature. The organic layer was washed with water $(150 \mathrm{~mL})$ to remove the catalyst. This procedure was repeated until the washing attained a neutral $\mathrm{pH}$. The organic layer was then cast onto Teflon dishes before drying in a vacuum oven at $50{ }^{\circ} \mathrm{C}$ for $24 \mathrm{~h}$.

\subsection{Measurements and Characterization Techniques}

FTIR spectra were recorded on a Perkin-Elmer 2000-FTIR using single beam transmittance onto a film of sample on ZnSe window in the range of 4,000-600 $\mathrm{cm}^{-1}$. The FTIR samples were prepared by swelling sample $(100.00 \mathrm{mg})$ with chloroform $(5 \mathrm{~mL})$. The sample solution was cast onto a Teflon mould and air dried. The thin film was dried in a vacuum oven at $50{ }^{\circ} \mathrm{C}$ for $1 \mathrm{~h}$ and was later transferred onto ZnSe window. 1D and 2D NMR spectra were obtained using a Bruker Avance $500 \mathrm{MHz}$ instrument in $\mathrm{CDCl}_{3}$ at $25{ }^{\circ} \mathrm{C}$. A $10.00 \mathrm{mg}$ sample was used for ${ }^{1} \mathrm{H}$ and J-Resolved Spectroscopy (JRES) while $50.00 \mathrm{mg}$ were used for the ${ }^{13} \mathrm{C}-\mathrm{NMR}$, distortion enhancement by polarization transfer (DEPT), heteronuclear multiple quantum coherence (HMQC), heteronuclear multiple bond coherence (HMBC) and correlation spectroscopy (COSY) analyses. The respective range of the spectra and number of scan for ${ }^{1} \mathrm{H}$ and for ${ }^{13} \mathrm{C}$-NMR measurements were $15-0 \mathrm{ppm}$ with 16 scans and 200-0 ppm with 15,000 scans, respectively. For quantitative ${ }^{13} \mathrm{C}$-NMR measurements, 1,000 scans were applied with 60 seconds relaxation delay. The number of scans applied for JRES, DEPT, HMQC, HMBC and COSY were 8, 2000, 128, 256 and 40 scans, respectively.

\subsection{Theoretical Treatments}

The FTIR semi-quantitative treatments were based on the band area of methyl, epoxide and $\mathrm{C}=\mathrm{S}$ functional groups. The percentage of epoxide in purified ENR-50 and the percentage dithiocarbonation of the epoxide were determined using Equations (1) and (2), respectively. In Equations (1) and (2), $\mathrm{N}_{\text {methyl }}$ is the normalized band area of the methyl signal, $\mathrm{A}$ epoxide sample is the band area of epoxide

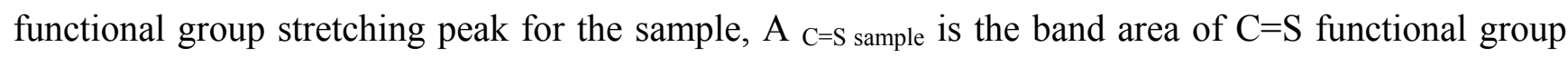
stretching peak for the sample, and $\mathrm{A}$ epoxide ENR-50 is the band area of respective functional group stretching peak in purified ENR-50:

$$
\begin{gathered}
\% \text { Epoxide }=\frac{\mathrm{N}_{\text {methyl }} \times \mathrm{A}_{\text {epoxide sample }} \times 100 \%}{\mathrm{~A}_{\text {epoxide ENR }-50}} \\
\% \mathrm{C}=\mathrm{S}=\frac{\mathrm{N}_{\text {methyl }} \times \mathrm{A}_{\mathrm{C}=\mathrm{S} \text { sample }} \times 100 \%}{\mathrm{~A}_{\text {epoxide ENR-50 }}}
\end{gathered}
$$

The ${ }^{13} \mathrm{C}$-NMR quantitative treatments were also used to determine the percentage of epoxidation in the purified ENR-50 and its five-membered ring cyclic dithiocarbonate derivative using Equations (3) and (4) below. In both equations, $\mathrm{I}_{\mathrm{C} 1}$ is the integral of $\mathrm{C}^{1}$ at $\delta 134.9 \mathrm{ppm}, \mathrm{I}_{\mathrm{E} 6 \text { epoxide }}$ is the integral of $\mathrm{E}^{6}$ at $\delta 61.0 \mathrm{ppm}$, and $\mathrm{I}_{\mathrm{E} 6 \text { cyclic }}$ is the integral of $\mathrm{E}^{6}$ at $\delta 94.0 \mathrm{ppm}$ : 


$$
\begin{gathered}
\% \text { Epoxide }=\frac{\mathrm{I}_{\mathrm{E} 6 \text { epoxide }} \times 100 \%}{\mathrm{I}_{\mathrm{C} 1}+\mathrm{I}_{\mathrm{E} 6 \text { epoxide }}} \\
\% \text { Cyclic dithiocarbonate }=\frac{\mathrm{I}_{\mathrm{E} 6 \text { epoxide }}+\mathrm{I}_{\mathrm{E} 6 \text { cyclic }} \times 100 \%}{\mathrm{I}_{\mathrm{C} 1}+\mathrm{I}_{\mathrm{E} 6 \text { epoxide }}+\mathrm{I}_{\mathrm{E} 6 \text { cyclic }}}
\end{gathered}
$$

\section{Conclusions}

The overlapping ${ }^{1} \mathrm{H}-\mathrm{NMR}$ signals of purified ENR-50 at $\delta 1.56,1.68-1.70,2.06,2.15-2.17 \mathrm{ppm}$ was successfully assigned to their respective triad sequences using the 2D NMR; HMQC, HMBC and COSY techniques. The signal at $\delta 1.56 \mathrm{ppm}$ was assigned to methylene protons of epoxidized isoprene, $\delta 1.68-1.70 \mathrm{ppm}$ to both methyl protons of isoprene and methylene protons of epoxidized isoprene. The signals at $\delta 2.06$ and 2.17-2.19 ppm were both assigned to the methylene protons of isoprene. The ${ }^{13} \mathrm{C}$-NMR chemical shifts were similar to those previously reported. However, the chemical shifts of methylene carbons were dependent on the types of vicinal neighbouring units in the triad sequence. The reaction of purified ENR-50 with $\mathrm{CS}_{2}$ formed the cyclic dithiocarbonate derivative of ENR-50 involving ring opening of the oxirane and the insertation of the C-S moiety at the oxygen attached to the quartenary carbon and methine carbon of epoxidized isoprene unit respectively. FTIR analysis showed that the $\mathrm{C}=\mathrm{S}$ and $\mathrm{C}-\mathrm{O}$ absorption bands appeared at 1096 and $1060 \mathrm{~cm}^{-1}$, respectively. ${ }^{1} \mathrm{H}-\mathrm{NMR}$ spectrum of cyclic dithiocarbonate derivative of ENR-50 displays splitting at $\delta$ 1.58-1.63 ppm and was assigned to the methylene protons of the respective epoxide and five-membered dithiocarbonate rings. Meanwhile, ${ }^{13} \mathrm{C}$-NMR showed two new carbon peaks assigned to the $>\mathrm{C}=\mathrm{S}$ and the quartenary carbon of five-membered cyclic dithiocarbonate ring. The FTIR semi-quantitative and ${ }^{13} \mathrm{C}$-NMR quantitative calculations revealed that approximately half of the epoxide units in the ENR-50 were converted to the dithiocarbonate derivative.

\section{Acknowledgments}

The authors would like to acknowledge the Universiti Sains Malaysia for the research grants: FRGS (304/PKIMIA/671029) and USM-RU-PRGS (1001/PKIMIA/841023) in support of this work.

\section{References}

1. Baker, C.S.L.; Gelling, I.R. Epoxidized Natural Rubber. In Development of Rubber Technology; Gelling, I.R., Ed.; Elsevier Applied Science: London, UK, 1987; Volume 4, p. 87.

2. Gelling, I.R. Modification of Natural Rubber with Peracetic Acid. Rubber Chem. Technol. 1985, $58,86-96$.

3. Jeerupun, J.; Wootthikanokkhan, J.; Phinyocheep, P. Effects of Epoxidation Content of ENR on Morphology and Mechanical Properties of Natural Rubber Blended PVC. Macromol. Symp. 2004, 216, 281-292.

4. Lee, S.Y.; Hassan, A.; Tan, I.K.P.; Terakawa, K.; Ichikawa, N.; Gan, S.N. Reaction of Palm Oil Based mcl-PHAs with Epoxidized Natural Rubber. J. Appl. Polym. Sci. 2010, 115, 2039-2043.

5. Gelling, I.R. Epoxidised Natural Rubber. J. Nat. Rubb. Res. 1991, 6, 184-205. 
6. Burfield, D.R.; Lim, K.L.; Law, K.S.; Ng, S. Analysis of Epoxidized Natural Rubber: A Comparative Study of D.S.C., N.M.R., Elemental Analysis and Direct Titration Methods. Polymer 1984, 25, 995-998.

7. Gelling, I.R. Epoxidized Natural Rubber. In Polymeric Materials Encyclopedia; Salamone, J.C., Ed.; CRC Press: Boca Raton, FL, USA, 1996; Volume 3 (D-E), p. 2192.

8. Bhattacharjee, S.; Bhowmick, A.K.; Avasthi, B.N. Hydrogenation of Epoxidized Natural Rubber in the Presence of Palladium Acetate Catalyst. Polymer 1993, 34, 5168-5173.

9. Gan, S.N.; Ziana, A.H. Partial Conversion of Epoxide Groups to Diols in Epoxidized Natural Rubber. Polymer 1997, 38, 1953-1956.

10. Derouet, D.; Brosse, J.C.; Challioui, A. Alcoholysis of Epoxidized Polyisoprene by Direct Opening of Oxirane Rings with Alcohol Derivatives. 2. Study on Epoxidized 1,4-Polyisoprene. Eur. Polym. J. 2001, 37, 1327-1337.

11. Saito, T.; Klinklai, W.; Kawahara, S. Characterization of Epoxidized Natural Rubber by 2D NMR Spectroscopy. Polymer 2007, 48, 750-757.

12. Bradbury, J.H.; Perera, M.C.S. Epoxidation of Natural Rubber Studied by NMR Spectroscopy. J. Appl. Polym. Sci. 1985, 30, 3347-3364.

13. Thames, S.F.; Gupta, S. Synthesis and Characterization of Pendent Hydroxy Fluoroesters of Secondary High Molecular Weight Guayule Rubber. J. Appl. Polym. Sci. 1997, 63, 1077-1089.

14. Furst, A.; Pretsch, E. A Computer Program for the Prediction of ${ }^{13} \mathrm{C}-\mathrm{NMR}$ Chemical Shifts of Organic Compounds. Anal. Chim. Acta 1990, 229, 17-25.

15. Pretsch, E.; Furst, A.; Badertscher, M.; Burgin, R. C13Shift: A Computer Program for the Prediction of ${ }^{13} \mathrm{C}$-NMR Spectra Based on an Open Set of Additivity Rules. J. Chem. Inf. Comput. Sci. 1992, 32, 291-295.

16. Mohamad, Z.; Ismail, H.; Chantara Thevy, R. Characterization of Epoxidized Natural Rubber/Ethylene Vinyl Acetate (ENR-50/EVA) Blend: Effect of Blend Ratio. J. Appl. Polym. Sci. 2006, 99, 1504-1515.

17. Noriman, N.Z.; Ismail, H.; Rashid, A.A. Characterization of Styrene Butadiene Rubber/Recycled Acrylonitrile-butadiene Rubber (SBR/NBRr) Blends: The Effects of Epoxidized Natural Rubber (ENR-50) As a Compatibilizer. Polym. Test. 2010, 29, 200-208.

18. Abu Bakar, M.; Ismail, J.; Teoh, C.H.; Tan, W.L.; Abu Bakar, N.H.H. Modified Natural Rubber Induced Aqueous to Toluene Phase Transfer of Gold and Platinum Colloids. J. Nanomater. 2008, 2008, 1-8.

19. Lee, H.K.; Ismail, J.; Kammer, H.W.; Bakar, M.A. Melt Reaction in Blends of Poly(3-Hydroxybutyrate) (PHB) and Epoxidized Natural Rubber (ENR-50). J. Appl. Polym. Sci. 2005, 95, 113-129.

20. Han, C.C.; Ismail, J.; Kammer, H.W. Melt Reaction in Blends of Poly(3-hydroxybutyrate-co-3hydroxyvalerate) and Epoxidized Natural Rubber. Polym. Degrad. Stab. 2004, 85, 947-955.

21. Mishra, J.K.; Chang, Y.W.; Kim, D.K. Green Thermoplastic Elastomer Based on Polycaprolactone/Epoxidized Natural Rubber Blend as a Heat Shrinkable Materials. Mater. Lett. 2007, 61, 3551-3554. 
22. Nghia, P.T.; Siripitakchai, N.; Klinklai, W.; Saito, T.; Yamamoto, Y.; Kawahara, S. Compatibility of Liquid Deproteinized Natural Rubber Having Epoxy Group (LEDPNR)/Poly (L-Lactide) Blend. J. Appl. Polym. Sci. 2008, 108, 393-399.

23. Nghia, P.T.; Onoe, H.; Yamamoto, Y.; Kawahara, S. Hydrogenation of Natural Rubber Having Epoxy Group. Colloid Polym. Sci. 2008, 286, 993-998.

24. Halimehjani, A.Z.; Ebrahimi, F.; Azizi, N.; Saidi, M.R. A Simple and Novel Eco-Friendly Process for the Synthesis of Cyclic Dithiocarbonates from Epoxides and Carbon Disulfide in Water. J. Heterocycl. Chem. 2009, 46, 347-350.

25. Giraudeau, P.; Akoka, S. Resolution and Sensitivity Aspects of Ultrafast $J$-resolved 2D NMR Spectra. J. Magn. Reson. 2008, 190, 339-345.

26. Viant, M.R. Improved Methods for the Acquisition and Interpretation of NMR Metabolomic Data. Biochem. Biophys. Res. Commun. 2003, 310, 943-948.

27. Macomber, R.S. A Complete Introduction to Modern NMR Spectroscopy; John Wiley \& Sons Inc.: New York, NY, USA, 1998; p. 77.

28. Shamsuzzaman; Salim, A. Synthesis of 1,3-Oxathiolane-2-Thiones by the Reaction of Steroidal Oxiranes with Carbon Disulfide. Tetrahedron Lett. 1997, 32, 5705-5708.

29. Conley, R.T. Infrared Spectroscopy, 2nd ed.; Allyn and Bacon Inc.: Boston, MA, USA, 1972; pp. 138-140, 194-197.

30. Kawahara, S.; Saito, T. Preparation of Carbonated Natural Rubber. J. Polym. Sci. A Polym. Chem. 2006, 44, 1561-1567.

31. Kawahara, S.; Chaikumpollert, O.; Sakurai, S.; Yamamoto, Y.; Akabori, K. Crosslinking Junctions of Vulcanized Natural Rubber Analyzed by Solid-state NMR Spectroscopy Equipped with Field-gradient-magic Angle Spin Probe. Polymer 2009, 50, 1626-1631.

32. Bruice, P.Y. Organic Chemistry, 3rd ed.; Prentice-Hall Inc: Upper Saddle River, NJ, USA, 2001; p. 448.

Sample Availability: Not available.

(C) 2012 by the authors; licensee MDPI, Basel, Switzerland. This article is an open access article distributed under the terms and conditions of the Creative Commons Attribution license (http://creativecommons.org/licenses/by/3.0/). 